This item was submitted to Loughborough's Research Repository by the author.

Items in Figshare are protected by copyright, with all rights reserved, unless otherwise indicated.

\title{
A review of laser engineered net shaping (LENS) build and process parameters of metallic parts
}

PLEASE CITE THE PUBLISHED VERSION

https://doi.org/10.1108/RPJ-04-2018-0088

\section{PUBLISHER}

Emerald Publishing Limited

\section{VERSION}

VoR (Version of Record)

\section{PUBLISHER STATEMENT}

This article is published under the Creative Commons Attribution (CC BY 4.0) license. Anyone may reproduce, distribute, translate and create derivative works of this article (for both commercial and non-commercial purposes), subject to full attribution to the original publication and authors. The full terms of this license may be seen at http://creativecommons.org/licences/by/4.0/legalcode

\section{LICENCE}

CC BY 4.0

\section{REPOSITORY RECORD}

Izadi, Mojtaba, Aidin Farzaneh, Mazher Mohammed, lan Gibson, and Bernard Rolfe. 2020. "A Review of Laser Engineered Net Shaping (LENS) Build and Process Parameters of Metallic Parts". Loughborough University. https://hdl.handle.net/2134/12625394.v1. 


\title{
A review of laser engineered net shaping (LENS) build and process parameters of metallic parts
}

\author{
Mojtaba Izadi and Aidin Farzaneh \\ Faculty of Science Engineering and Built Environment, Deakin University, Geelong, Australia \\ Mazher Mohammed \\ School of Design and Creative arts, Loughborough University, Loughborough, England \\ Ian Gibson \\ Department of Design, Production and Management, University of Twente, Netherlands, and \\ Bernard Rolfe \\ Faculty of Science Engineering and Built Environment, Deakin University, Geelong, Australia
}

\begin{abstract}
Purpose - This paper aims to present a comprehensive review of the laser engineered net shaping (LENS) process in an attempt to provide the reader with a deep understanding of the controllable and fixed build parameters of metallic parts. The authors discuss the effect and interplay between process parameters, including: laser power, scan speed and powder feed rate. Further, the authors show the interplay between process parameters is pivotal in achieving the desired microstructure, macrostructure, geometrical accuracy and mechanical properties.

Design/methodology/approach - In this manuscript, the authors review current research examining the process inputs and their influences on the final product when manufacturing with the LENS process. The authors also discuss how these parameters relate to important build aspects such as melt-pool dimensions, the volume of porosity and geometry accuracy.

Findings - The authors conclude that studies have greatly enriched the understanding of the LENS build process, however, much studies remains to be done. Importantly, the authors reveal that to date there are a number of detailed theoretical models that predict the end properties of deposition, however, much more study is necessary to allow for reasonable prediction of the build process for standard industrial parts, based on the synchronistic behavior of the input parameters.

Originality/value - This paper intends to raise questions about the possible research areas that could potentially promote the effectiveness of this LENS technology.
\end{abstract}

Keywords Input process parameters, LENS, Outputs

Paper type Literature review

\section{Introduction}

Additive manufacturing (AM) is a highly developed fabrication technique, which fundamentally creates a three-dimensional object using a layer-by-layer build process. The first recognized patent for AM technology was by Charles Hull for what became known as stereo lithography. $\mathrm{He}$ is also credited for the development of the standardized interfacing model format, STL, which is also named after this manufacturing process. As these early days, AM has been gaining in popularity because of the inherent advantages when compared with conventional manufacturing methods such as casting and machining. As designs are made additively rather than by subtractive means, there can be substantial saving on raw material consumption

The current issue and full text archive of this journal is available on Emerald Insight at: https://www.emerald.com/insight/1355-2546.htm

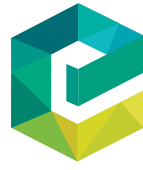

Rapid Prototyping Journal

26/6 (2020) 1059-1078

Emerald Publishing Limited [ISSN 1355-2546]

[DOI 10.1108/RPJ-04-2018-0088] and wastage. Equally, for prototyping purposes, there are almost a limitless number of possibilities to examine alternative design iterations. However, the true power of AM is the symbiotic relationship to modern computer aided design (CAD) and the power to incorporate design complexities. By contrast, traditional manufacturing processes require considerable cost, both in terms of time and expense, when complexity is increased (Gibson et al., 2010). The typical phases associated with the AM production cycle are illustrated in Figure 1. The first stage is the digital modeling using some form of CAD. The digital model is then typically converted into

\footnotetext{
(C) Mojtaba Izadi, Aidin Farzaneh, Mazher Mohammed, Ian Gibson and Bernard Rolfe. Published by Emerald Publishing Limited. This article is published under the Creative Commons Attribution (CC BY 4.0) license. Anyone may reproduce, distribute, translate and create derivative works of this article (for both commercial and non-commercial purposes), subject to full attribution to the original publication and authors. The full terms of this license may be seen at http://creativecommons.org/licences/by/4.0/legalcode
}

Received 9 April 2018

Revised 21 September 2018

28 May 2019

4 November 2019

Accepted 13 February 2020 
an STL file, which has become the current AM standard. This is then converted into a machine code format, containing information relating to the build parameters for a given printer, before manufacturing commences. Depending on the specific AM technology either a reusable print bed can be used, as with many polymer-based technologies, or a sacrificial bed is used, as with metal printing techniques. With reusable beds, printed parts can simply be removed for post-processing. However, with metal printing, wire cutting is normally required to remove parts from the sacrificial bed. Following part removal, postprocessing may be required to remove excess build material used to support overhanging structures or to improve the surface finish and integrity of the part, before it is ready for use (Gibson et al., 2010).

Several mainstream industries have taken advantage of AM technology owing to its uniqueness both regarding prototyping and production.

Historically, the automotive industry were the primary users of AM to increase the speed of new product development and rapidly send parts to market. Equally, the ability to create highly complex, high-performance parts has seen several aerospace companies embrace the use this technology for production of parts within airplane cabins and engine components (Joshi and Sheikh, 2015). Additionally, medical practitioners and device companies have leveraged the benefits of AM technology, initially creating medical models for preclinical planning (Stoker et al., 1992). Following from this early use, the sector has matured rapidly and now allows for the fabrication of implants (Mohammed et al., 2016; Osman et al., 2017), orthotics (Chen et al., 2016; Fitzpatrick et al., 2017) and prosthetics (Mohammed et al., 2017). It is believed that as AM matures over the coming years, usage of this technology is likely to become more widespread and likely capture a greater portion of the global manufacturing market (Campbell et al., 2012).

The majority of commercial applications use polymer or metallic printing, with metal printing currently demanding most attention (Gibson et al., 2010). There are three common

Figure 1 Additive manufacturing eight stages

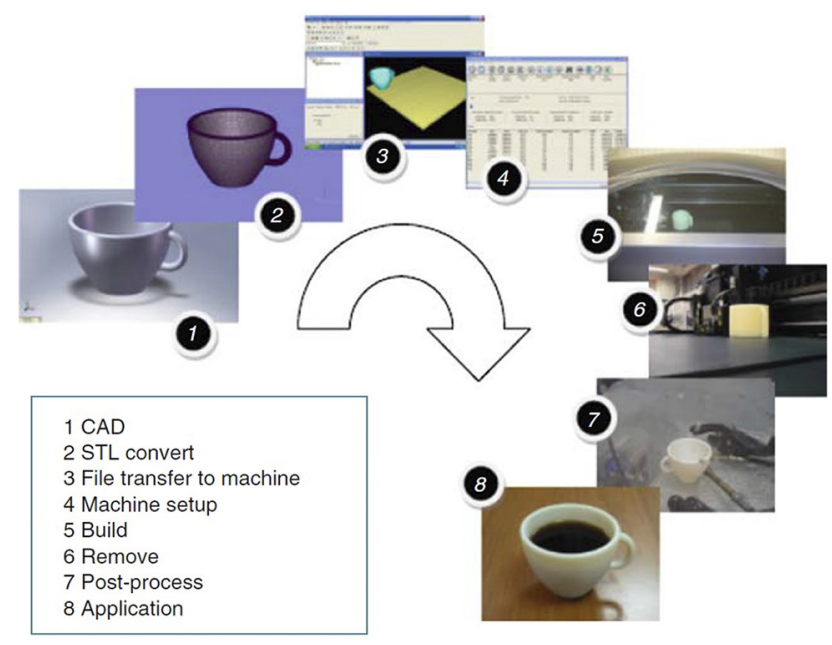

Source: Gibson et al. (2010) metal AM systems according to American Society for testing and materials (ASTM) standard; powder bed fusion (PBF), directed energy deposition (DED) and sheet lamination (Terminology, 2015). The most common is PBF with processes such as electron beam melting (EBM) (Murr et al., 2012), selective laser melting (SLM) (Frazier, 2014) and laser engineered net shaping (LENS) as the most well-known DED technologies. PBF and LENS share similarities in that they both perform melting of metallic powders using a directed thermal energy source, such as a laser or an electron beam, to complete metallurgical bonding for each successive layer (Frazier, 2014; Syed et al., 2005).

PBF systems normally comprise a confined thermal beam, powder bed, movable table/fabrication piston, powder delivery system and a roller, as can be seen in Figure 2(a) (Thompson et al., 2015). Powder is melted selectively by a laser or electron beam with the scanning or melting pattern comprising pulses or continuous lines. Once one layer is completed, the table moves down and a roller or scraper distributes a new layer of powder before the process repeats to selectively melt the subsequent layer. The primary advantages of this process are the ability to produce high-resolution features, alongside the control of a part's dimensional accuracy (Frazier, 2014; Vandenbroucke and Kruth, 2007; Yadroitsev et al., 2007).

However, a typical DED system generally comprises a laser, material delivery nozzles, fixed substrate and adjustable deposition head, as can be seen in Figure 2(b) (Thompson et al., 2015). By contrast to PBF systems, energy delivery and material deposition are focused on the same region, allowing for greater control of material feed. Additionally, the print platform remains fixed and the laser beam is moved in the $Z$ direction. As with PBF, DED processes require the use of inert gas to reduce oxidation rates (Thompson et al., 2015). The most common DED process is LENS, where powder delivery is controlled using up to four delivery nozzles (Palcic et al., 2009), as illustrated in Figure 2(c). Variations of this technology exist and are largely centered on the coaxial beam and powder delivery (Wen et al., 2009; Pinkerton, 2007; Syed et al., 2006; Keicher and Miller, 2001). It is believed that the differing directional powder delivery systems could result in different mechanical properties and dimensional accuracies. However, no specific strategy has proven to be superior. With the DED process, there are three types of lasers, which are typically used; $\mathrm{CO}_{2}, \mathrm{Nd}$, namely, YAG and fiber lasers. The choice of laser significantly influences the powder consolidation during the build process, which, in turn, influences the micro-structure and mechanical properties. This is primarily attributed to laser absorptivity of a respective material, and which, in turn, depends on the laser wavelength. Equally, the operative metallurgical mechanism for powder densification is determined by the input laser energy density (Gu et al., 2012; Kobryn and Semiatin, 2001).

With respect to DED and powder feed processes, there are current a number of excellent reviews that have been conducted. Frazier (2014) explored the material science, processes and business consideration of metal AM. Lewandowski and Seifi (2016) provided a review of mechanical properties of all metal AM process. In addition, Herzog et al. (2016) reviewed several materials microstructure of samples deposited in SLM, EBM and DED. Despite the insights gained 
Figure 2 (a) Powder bed fusion schematically, (b) direct energy deposition (LENS). Reproduced from Thompson et al. (2015) with the permission from Elsevier and (c) photograph of a LENS MR-7

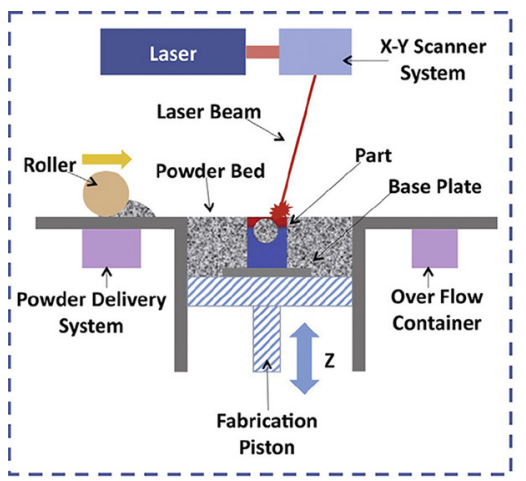

(a)

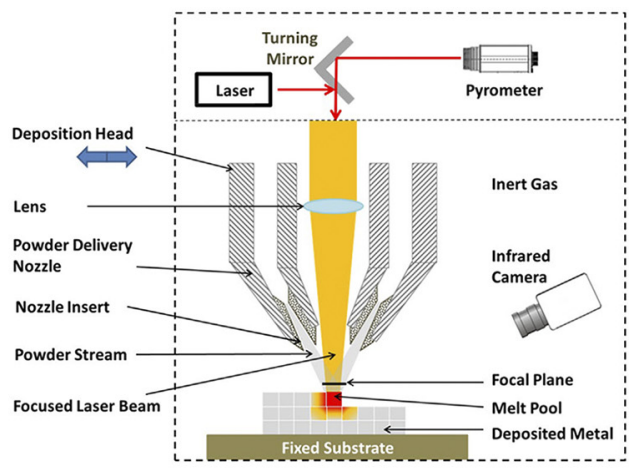

(b)

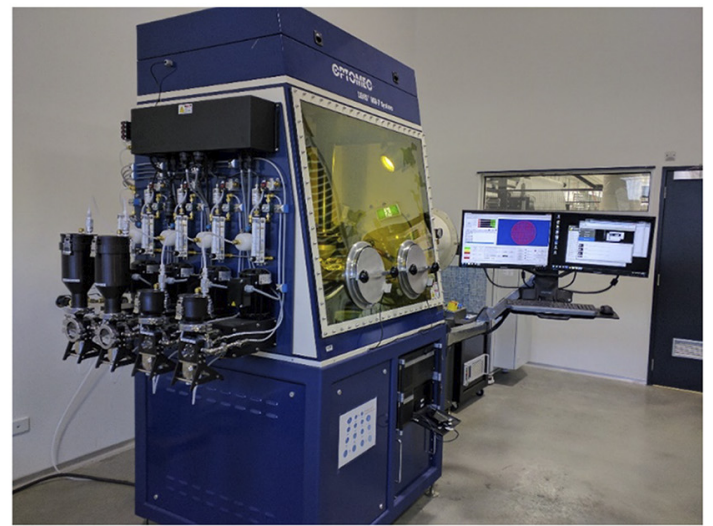

(c)

all reviews have neglected an in-depth discussion of build process parameters. Some insights on DED processes were presented by Thompson et al. (2015), but were limited to discussions primarily on different types of DED and their build attributes such as solidification, morphology, etc. and not focused on the effects of varying specific LENS process parameters. In this review, we shall focus primarily on fiber laser-based LENS technology and discuss in detail facets relating to the processing parameters and their potential optimization. The review will have the following structure. The LENS process will be briefly outlined. Hence, the work on the controllable process parameters is then reviewed. This is followed by a survey of the parameters that have an effect on the LENS process but are not controlled by the process. This leads to a discourse on the outputs of the LENS process and a discussion of the future directions of the LENS process.

\section{Laser engineered net shaping}

Prior to any in-depth discussion on process parameters, it is useful to explore the evolution, advantages, disadvantages, post processing and application of LENS to provide a clearer picture of this technology's capability.

\subsection{Laser engineered net shaping evolution}

To appreciate the evolution leading to the LENS technology, we should give credit to laser cladding. Laser-based material processing was a significant area of development in the 1970 s when power and efficiency of commercial lasers grew rapidly. Laser cladding was first used by Gnanamuthu at Rockwell International Corporation in California. Steen and Weerasinghe at Imperial College, UK also had a notable impact on laser cladding technology, presenting laser cladding using powder injection (Toyserkani et al., 2004). Powell (1983) also investigated this powder laser cladding technique and in 1988, he and Steen, developed a theoretical model and analysis technique for pre-placed laser cladding (Powell et al., 1988).

In the late 1990s, laser cladding for rapid prototyping was introduced. At the University of Illinois, Urbana, the Mazumder research group developed a method for rapid prototyping, which was later named direct metal deposition and later called DED. Their research evaluated building parts in one and two dimensions. Many other research and development groups investigated methods for prototyping metallic parts based on laser cladding by powder injection. In the late 1990s, a development group at Sandia National Laboratory, operated by Lockheed Martin Corporation and funded by US Department of Energy, initiated research toward the development of a laser near-net-shape fabrication method. Afterward on the technology was called LENS (Toyserkani et al., 2004). LENS has since been commercialized by Optomec in 1998 and is still under continued development. 


\subsection{Advantages of laser engineered net shaping}

Salient features of LENS technology are the unconstrained powder feed, which in some LENS models can realize five-axis control. Additionally, the typical build volume is comparatively large and can be $900 \times 1,500 \times 900 \mathrm{~mm}$ (LENS 1500, 2018). Compared to most commonly used PBF technologies (Salmi et al., 2018), this allows for the creation of much larger parts while simultaneously reducing relative powder demands (Dutta and Froes, 2015).

LENS, machines generate smaller melt-pools, allowing for higher solidification/cooling rates as compared with conventional manufacturing processes like casting (Balla et al., 2010a; Balla et al., 2010b). However, a truly defining feature of the LENS process is the ability to fabricate with multiple materials and create functionally graded materials, owing to the multiple powder feed lines (Espana et al., 2010).

LENS can also be used to fabricate products using materials with high melting temperatures, which have a greater tendency to oxidize using conventional manufacturing methods. It can build such elements in the absence of oxygen to create solid or non-uniform porous structures (Balla et al., 2010a; Balla et al., 2010b). In addition, manufactured parts are found to be more robust, less brittle and less prone to cracking at low stress (Bandyopadhyay et al., 2010). This is believed to be due to the LENS process realizing a more defect-free interfacial bond between the layers for optimization within a given process window (Balla and Bandyopadhyay, 2010). Another possibility with the LENS process is the creation of complex porous structures. Porosity can be introduced not only through design architecture but also inherently within the bulk of the processed material itself.

Furthermore, the LENS build process is not constrained by the requirement to commence building on a level platform, as with $\mathrm{PBF}$, providing opportunity to build upon pre-existing parts. This can be useful when considering repair of worn or damaged components (Frazier, 2014).

\subsection{Disadvantages of laser engineered net shaping}

All metal AM systems exhibit uneven heating and cooling due to the large temperature gradients between the ambient environment, laser focal point, part layers/build plate and the melt-pool. This can result in difficult to predict thermal control. The situation for the LENS is exacerbated by layers closer to the substrate having a higher cooling rate in comparison with higher layers. Unlike PBF, there is no unmelted powder around the melt-pool to help create a more even thermal gradient, which would consequently decrease residual stresses. Hence, residual stress is significantly higher with LENS, which could possibly affect part precision or even lead to part collapse during deposition (Wong and Hernandez, 2012). In addition, PBF can use the unmelted powder as a support structure while LENS cannot realize this feature.

Another effect of the uneven heating and cooling rate in LENS can be non-uniformity in microstructure and macrostructure with respect to the height of build. Furthermore, complex thermal wave effects have been observed during deposition and when combined with build height irregularities, have been found to significantly affect mechanical properties of a manufactured part (Balla et al., 2010a; Balla et al., 2010b, 2010b; Hofmeister and Griffith,
2001; Yadollahi et al., 2015). It is noted that this further influences the mechanical properties differently for different materials (Amine et al., 2014; Yan et al., 2016). Indeed, the dimensional accuracy of a LENS manufactured product has always been a challenge, with no clear general protocol to attain satisfactory build outcomes particularly when fabricating complex geometry parts. As with all additive based build processes, each successive deposition highly depends on the previous layer geometry and the height. In LENS, if the previous layer is thinner or thicker than designed, then the dimension of melt-pool may vary due to an incorrect laser focal point (Pi et al., 2011; Lu et al., 2010; Shamsaei et al., 2015). Unsurprisingly, the build accuracy is entirely related to the optimization of build process parameters for a given metallic powder to produce a respective model at a desired layer height. Consequently, to resolve build irregularities more time is generally needed for post processing as compared to $\mathrm{PBF}$ technologies.

In addition, based on the nature of AM there is a staircase effect that effects surface roughness as a result of manufacture layer by layer (Kaji and Barari, 2015). On DED in particular, there could be many partial melted particles, which are associated with the surface. This could increase the surface roughness for deposited parts (Dinda et al., 2008). Low surface quality can negatively affect the mechanical properties of the finished part. For instance, by increasing the surface roughness the fatigue life decreases on EBM fabricated Ti-6Al$4 \mathrm{~V}$ parts (Frazier, 2014). On samples produced by LENS, the surface roughness is sometimes higher than EBM (Zhai et al., 2016), therefore, potentially leading to lower fatigue life when using the LENS process.

\subsection{Laser engineered net shaping post processing}

Annealing and heat treatment are the most common forms of post-processing researchers currently conduct on LENS fabricated parts (Yadollahi et al., 2015; Sterling et al., 2016; Durejko et al., 2016; Zhai et al., 2016). Yadollahi et al. (2015) found a protocol of heat treatment for $2 \mathrm{~h}$ at $1,150^{\circ} \mathrm{C}$ followed by air cooling of stainless steel 316 results in a homogeneous microstructure, removing laser track footprints and deposition layer artefacts. Other studies found heat treatment of Ti-6Al$4 \mathrm{~V}$ for an hour at $760^{\circ} \mathrm{C}$ within a vacuum followed by air cooling led to stress relief and a decomposition of martensitic phase, resulting in a significant increase in tensile strength but decrease in ductility (Zhai et al., 2016).

In addition to heat treatment, hot isostatic pressing (HIP) is another post processing technique that has been studied. Joseph et al. (2018) using LENS deposited three high entropy alloys based on $\mathrm{Al}_{\mathrm{x}} \mathrm{CoCrFeNi}$ with aluminium molar fractions $(x)$ of $0.3,0.6$ and 0.85 . They studied the effect of HIP on the microstructure and mechanical properties. Comparing asdeposited and HIP-processed $\mathrm{Al}_{0.3}$, HIP noticeably improved the tensile ductility and work hardening related to dissolution of grain boundary particles that were evident in the asdeposited condition. On the other hand, for HIP-processed $\mathrm{Al}_{0.6}$ the tensile ductility was reduced compared with asdeposited sample. This suggested the development of coarse B2 precipitates in the inter-phase and grain boundaries. Finally, the HIP-processed $\mathrm{Al}_{0.85}$ lost ductility significantly compared with as-deposited samples. This is due to HIP- 
processing resulting in coarsening of the microstructure and the formation of $\sigma$-phase precipitates.

There are other post process treatments such as ageing (Meneghetti et al., 2017; Shun and Du, 2009; Zadi-Maad and Basuki, 2018), homogenizing (Kao et al., 2009) and thermomechanical processing (Stepanov et al., 2015; Kuznetsov et al., 2012). However, to the best knowledge of the authors these have not been used on LENS deposited samples.

\subsection{Laser engineered net shaping application}

LENS technology can be used to fabricate parts for applications in key industries such as medical and aerospace (Guo and Leu, 2013; Gurrappa, 2003; Camacho et al., 2017; Dutta and Froes, 2017). Compared to many traditional metal AM build processes, LENS has many unique characteristics, which allow for a range of interesting opportunities for part production. The first such attribute stems from the ability of LENS to create functionally graded porous structures, which has been exploited for orthopaedic implant applications. Figure 3(a) shows various LENS fabricated hip stem implants, each with graded levels of intrinsic porosity resulting from the build process to allow for the process of bone osseointegration. Another major advantage of the LENS process is that as the material is delivered to a build area, manufacturing can be performed on objects of uneven surfaces and without the need for a powder bed. This opens up a range of interesting possibilities with respect to using the build process to build additional components or to repair complex, geometry parts. LENS is also highly suited to such applications owing to the high level of environmental control, which eliminates issues relating to part oxidation during manufacturing as parts are processed in an inert environment. Figure 3(b) shows one such example, where LENS was used to repair a bladed rotor. Beyond these standalone advantages, LENS is also very effective at creating high value parts. Figure 3(c) shows a $1 / 6$ scale mixing nozzle for a gas turbine exhaust for Bell helicopter made by LENS.

\section{Controllable laser engineered net shaping input parameters}

This section discusses more closely the parameters that can be controlled by the machine operator either prior to or during the build process. LENS provides flexibility to use non-proprietary materials in the build process, opening up endless possibilities with respect to existing and future metal alloy combinations. To realize this potential requires considerable concerted effort to refine build parameters based on the intrinsic characteristics of materials and their responses to achieve respective layer heights and resolutions. Critical build parameters discussed will include laser power, scan speed, powder feed rate, hatch distance, laser focal distance and deposition pattern. Ultimately, these parameters and their interplay dictate the overall quality of the final build and require optimization to ensure build integrity.

\subsection{Laser power}

In the LENS process, the laser is primarily used to liquefy metallic powder to form a melt-pool, which solidifies upon cooling to form the build voxel of a respective layer. This form of building process is not unique to LENS and has widely been exploited in welding (Benyounis et al., 2005; Akman et al., 2009; Sathiya et al., 2012), cladding (Gedda et al., 2002; Smurov, 2008; Yang, 2009; Yevko et al., 1998) and more recently in PBF AM (Khairallah et al., 2016; King et al., 2015; Yadroitsev et al., 2010). Therefore, the influence of laser power has been widely explored and shown to affect mechanical properties of a metal part. The majority of current studies have focused on non-laser welding. Although these studies could be useful for the understanding of laser based processes, there is limited insight due to differing heat distribution characteristics. Therefore, examination of laser power characteristics is an emerging area of LENS research.

Ultimately, laser power is possibly the most important process parameter in LENS, where variation of this parameter can have the most significant effect on a part's mechanical properties. For instance, when a dense structure is required, the laser power could be increased to avoid partial melting zones (porous structures) but doing so can also lead to undesired microstructural changes (Balla et al., 2009). It has been observed in some cases that grain size grows by increasing laser power, consequently reducing hardness and potentially affecting other mechanical characteristics (Balla et al., 2010a; Kobryn et al., 2000; Wang et al., 2008). For instance, it has been demonstrated for titanium samples that if laser power

Figure 3 (a) Hips fabricated by LENS (Espana et al., 2010); (b) a repaired blisks using LENS (LENS Blisk Repair Solution, 2014) and (c) 1/6 scale mixing nozzle for gas turbine exhaust for Bell helicopter produced by LENS (Guo and Leu, 2013)

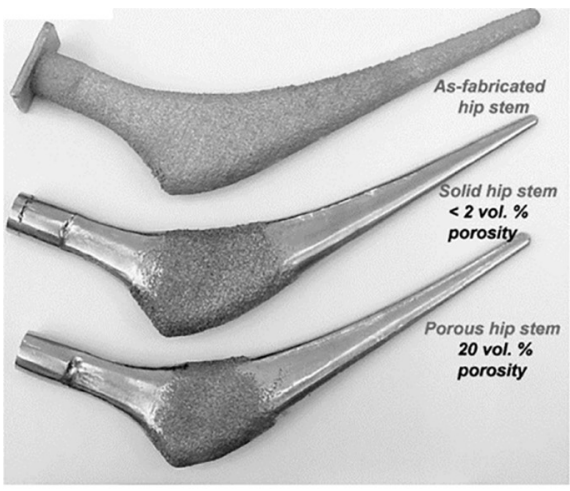

(a)

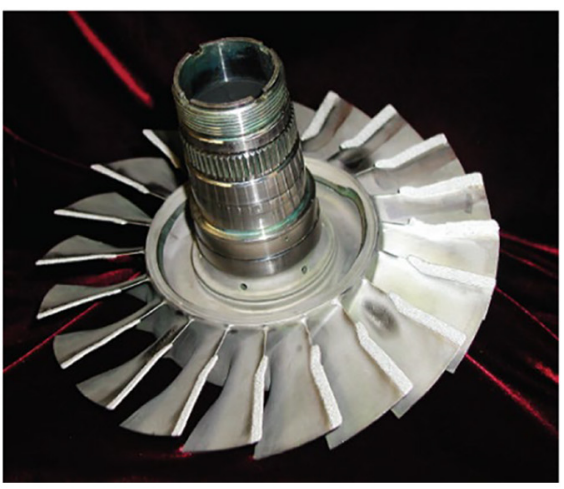

(b)

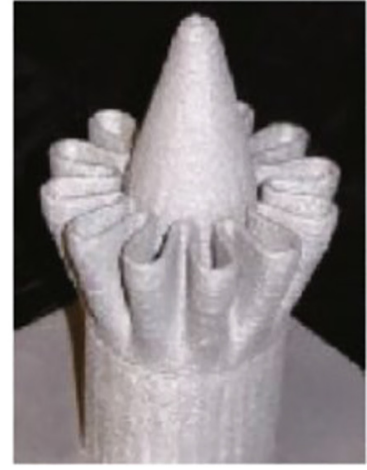

(c) 
increases from $250-300 \mathrm{~W}$ while other parameters are kept constant, part stiffness increases by more than three times (Krishna et al., 2007). Increasing laser power could also increase the residual stress between layers (Pratt et al., 2008). In some cases, the residual stress can affect material deposition, particularly for immiscible alloys such as when depositing brass on an AISI 410 substrate (Vandenbroucke and Kruth, 2007). Vandenbroucke et al. demonstrated that for powers more than $450 \mathrm{~W}$, brass layer delaminated occurred during the deposition process. However, this was most pronounced for the initial rather than subsequent layers.

Furthermore, laser power can affect surface roughness. Zhai et al. (2016) conducted an experiment on the LENS process using Ti-6Al-4V to study the surface roughness. They reduced laser power from $780-330 \mathrm{~W}$, which resulted in a reduction of surface roughness from 63.9 to $30.6 \mu \mathrm{m}$.

\subsection{Scan speed}

Scan speed seems to be the second most critical process parameter and refers to the relative translational speed of the laser focal point. Increasing the scan speed decreases the energy density imparted on the build surface for a constant laser power and frequency. Similar to laser power, this parameter affects melt-pool size and so potentially influences build integrity and resulting part mechanical properties. By increasing scan speed, the width and depth of melt-pool decreases due to a reduction in the imparted energy from the laser (Ferguson et al., 2015; Xiong et al., 2012), but somewhat counter-intuitively the deposited line has been observed to become wider and thicker (Bandyopadhyay et al., 2010; Kobryn et al., 2000; Krishna et al., 2007; Lewis and Schlienger, 2000).

In theory, increasing scan speed can decrease build time. However, physical limits exist where the resulting decrease in imparted energy on the build surface results in partially melted regions. This may be important particularly for layers consisting of two different materials with respect to the forming of a metallurgical bond (Espana et al., 2010; Balla et al., 2009). Furthermore, another effect of changing scan speed is the change in cooling rate, which can affect the resulting microstructure of the processed material. It has been found that increased scan speeds lead to higher cooling rates, resulting in smaller grain size, as grains have less time to grow (Kobryn et al., 2000). Moreover, it seems increasing scan speed beyond experimentally determined thresholds may lead to increased porosity in the bulk of the material, a lack of fusion porosity and decreased ductility (Pegues et al., 2017). Finally, it seems when scan speed increases, true fracture strain decreases, resulting in less ductility for Ti-6Al-4V. Reduction in ductility is most likely a consequence of a greater fraction of $\alpha$, phase due to more rapid heating and cooling along the beam path (Pegues et al., 2017).

\subsection{Powder feed rate}

Powder feed rate also plays an important role in LENS and relates to the speed and volume of metallic powder introduced to the melt-pool. Similar to the previous parameters, changing this can result in different mechanical properties (Bandyopadhyay et al., 2010; Krishna et al., 2007). For instance, when feed rate decreases, there may be an insufficient powder to fill the gap between two parallel lines, hence creating porous zones. Conversely, high feed rate may result in a thicker layer, which compromises the integrity of the subsequent build layers or introduces part non-uniformities (Kummailil et al., 2005). Another possible effect of excessive powder could be the creation of a masking region surrounding the melt-pool, which can lead to reduced absorption of laser energy (Paul et al., 2006).

Common powder sizes used for LENS range between 50 to $150 \mu \mathrm{m}$. Using bimodal powder distribution has the potential to decrease defects, particularly unwanted porosity (German, 1992). The effect of powder size distribution and density still need to be examined for most powder AM processes (Hebert, 2016). It should be noted that powder delivery for PBF processes are fundamentally simpler than DED, and a more uniform powder density distribution can be expected in PBF, as described in Section 1. In the LENS process a rotor takes the powder from feeders and then gas carries it to nozzles. When optimizing the feed rate for a given source powder, the LENS operator runs the feed system to ascertain the average flow rate in grams per min. This value is used in predicting the melt-pool characteristics. This method can realize stable average powder delivery densities. However, there is likely to be minor variances in the instantaneous powder density due to fluctuations in the average particle size and group velocity. The consequence of this is a reduction in build accuracy resulting from minor variances in the melt-pool size. Therefore, there is a need for a better understanding of the governing process to optimize build consistency. Furthermore, this must be related to a new metric we call the "powder capture rate," which relates to the interplay and synchronicity of this parameter with others in governing the overall melt-pool consistency.

To study the impression of powder capture rate, Haley et al. (2018) investigated the entrance of powder particles to a meltpool using four high-speed cameras $(\geq 10,000 \mathrm{fps})$. This resulted in a mathematical relationship to demonstrate how particle self-shielding ultimately limits the powder capture efficiency of LENS.

\subsection{Hatch distance}

Hatch distance can be defined as a cross-sectional distance between two scan lines (Balla et al., 2010b) and governs the attainable smallest feature size during the AM process. Figure 4(a) illustrates the relationship between scan line, hatch distance and melt-pool size. Effectively the hatch distance must be optimized based on the perceived size of the melt-pool to ensure the consistency of the formed $x-y$ layer within a part. Should the hatch distance be too small relative to the melt-pool, an excess of material will be formed on a layer resulting in build inconsistencies. Equally, when the hatch distance is too large relative to the size of the melt-pool, a lack of material will be formed on a layer leading to localized porosities. Some studies examined this effect to create a controlled porous structure, as can be seen in Figure 4(b) (Bandyopadhyay et al., 2010). Although a porous structure can arise by varying other parameters such as scan speed and laser power, the influence of changing hatch distance results in more profound variations. This effect greatly decreases the part stiffness (Krishna et al., 2007). Additionally, it has been found that using a hatch distance variation could result in greater uniformity in shape 
Figure 4 (a) Figure illustrating hatch distance relative to the scan line and melt-pool and (b) various samples of designed porous structure

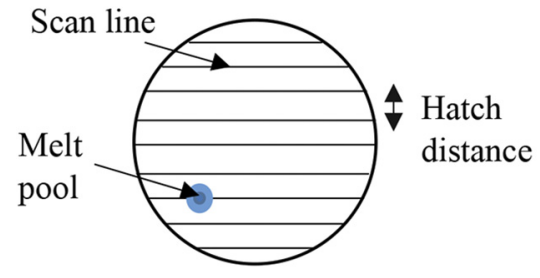

(a)

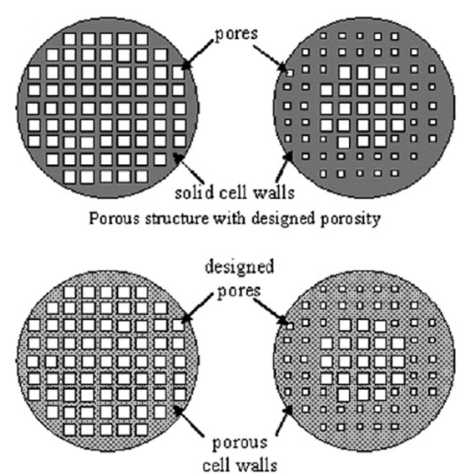

(b)

Source: Reproduced from Krishna et al. (2007) with the permission from Elsevier

and pore distribution within the structure (Krishna et al., 2007; Kummailil et al., 2005).

\subsection{Focal distance}

With respect to LENS, focal distance refers to the optimal convergence of both the maximum laser intensity and the localized spatial concentration of the powder beam, as illustrated in Figure 5(a). Failure to achieve an optimal focal distance can not only affect the perceived laser power at the build surface but also distribution of the powder, which can impact the geometry of the melt-pool. Maximum laser intensity can be achieved when the substrate/previous layer is located at or near the focal point of the laser. If the working distance is greater than optimal focal distance, the laser power becomes less localized and distributed over a larger area, while the powder spreads over a larger than desired working area.
Combined, this results in the melt-pool diameter becoming larger and height smaller, resulting in unpredictable variations in the scan line created (Xiong et al., 2009).

Conversely, if the work distance is shorter than the optimal focal distance, the laser power again becomes less localized and distributed over a larger area. Now, the powder progressively moves away from the desired focal point, until no powder is delivered to the area encompassing the laser. In this instance, the melt-pool diameter becomes progressively larger until a critical point where the powder cannot reach the laser area and the melt-pool is no longer created (Xiong et al., 2009), as illustrated in Figure 5(b). Ultimately, to maintain build consistency the focal distance is critical, however interestingly there exist possibilities to explore the build properties close to the focal point and leveraging these into the build process. For instance, Sharman et al. (2018) reported that the manipulation of focal distance for parts fabricated

Figure 5 (a) A schematic of working distance illustrating the balance of focusing both the laser and powder beams and (b) illustration of the resulting scan line over different working distances
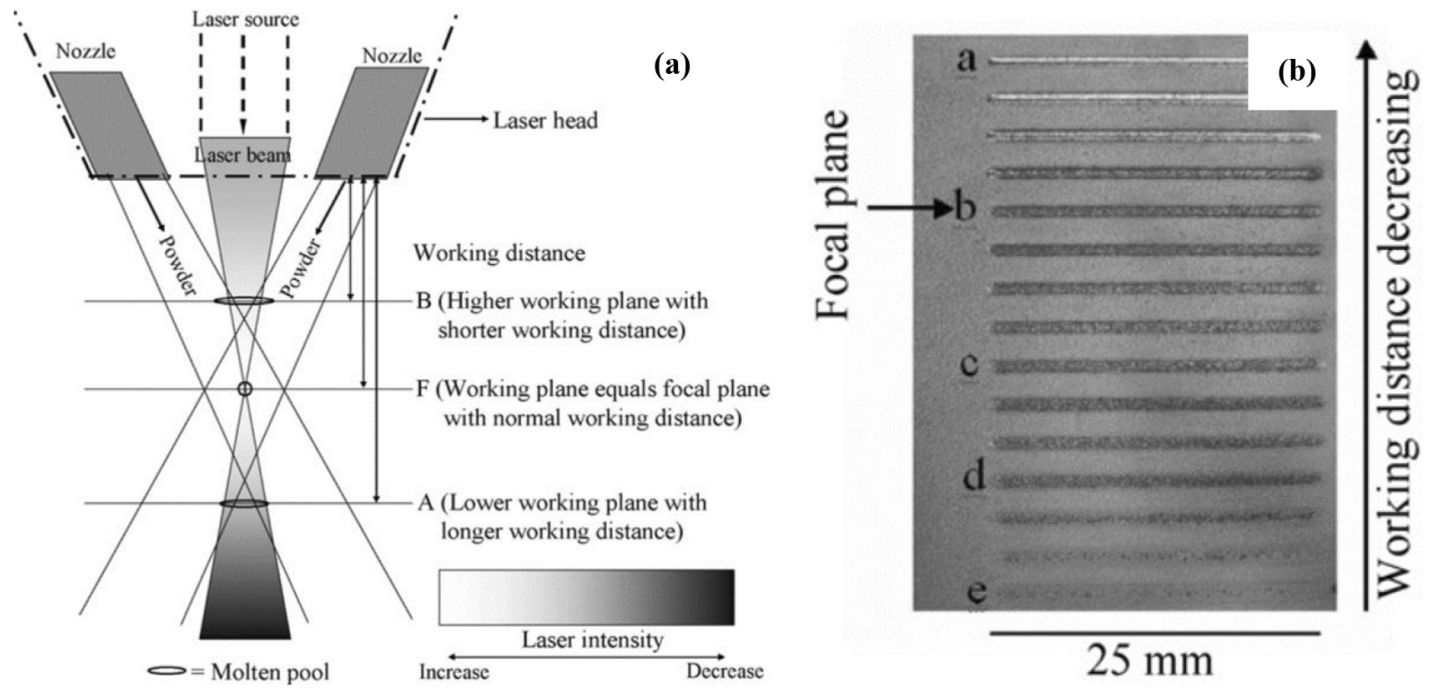

Source: Reproduced from Xiong et al. (2009) with the permission from Elsevier 
from titanium aluminide can result in a crack-free deposition. The researchers compared the quality of deposition with different laser power, scan speed and focal distance. Adjusting the focus position of laser above focal distance could control the cooling rate by preheating the powder particles just before they enter the molten-pool. This could result in reduction of cooling rate below the critical level that causes cracking (Sharman et al., 2018).

\subsection{Deposition pattern}

As with PBF, in LENS the deposition pattern refers to the pattern traced out by the laser during the build process. Some pattern examples are illustrated in Figure 6(A). Deposition pattern appears to affect residual stress, deflection, substrate distortion, macro-structure and mechanical properties such as tensile strength and elongation (Nickel et al., 2001; Yu et al., 2011; Dai and Shaw, 2002). LENS has a default deposition pattern, specifically for bulky items, which can be seen in Figure 6(B). Firstly, the outer contour is deposited (Figure 6B-1), before the laser reverse rasters to form hatch lines. The subsequent layer is then formed by deposition of the outer contour (Figure 6B-2), followed by depostion of another outer contour (Figure 6B-3). Finally, it deposits perpendicular laser raster to form the hatch lines (Figure 6B-4). It is believed that there exist opportunities to explore alternative deposition patterns.

In addition to the investigation of large area planar deposition, Wang et al. (2018) studied the effect on deposition patterns on an angled, overhanging thin wall of $17-4 \mathrm{PH}$ stainless steel thoughout the $Z$ build direction. They concluded that in unidirectional deposition the wall structure suffers an uneven surface and cavity at the end of the deposition path. Using a reciprocating deposition method, both ends were more even and symmetical.

\section{Fixed input parameters}

Beyond the controllable parameters for LENS, there are a number of parameters that are intrinsic and so remain fixed during a respective build process. Generally, such parameters relate to the intrinsic material properties of the powder (type, morphology and purity), the nature of the laser (wavelength), build atmosphere and thermal relaxation properties. Feasibly between build processes these parameters can be controlled and adjusted to varying degrees and so we shall discuss their significance in the overall LENS build process.

\subsection{Powder morphology}

This parameter is related to the overall geometry of the powder used in the build process. It has been found for both LENS and PBF processes that powder size can affect the quality of deposition and the smallest attainable build feature. Using finer powders potentially reduces the required heat to complete melting. As the fabrication of amorphous structures requires a relatively high cooling rate and complete melting, using a finer powder would be more logical instead of applying higher power (Balla and Bandyopadhyay, 2010). It is recommended to use spherical powder with 50 to $150 \mu \mathrm{m}$ diameter (Xiong et al., 2009; Zheng et al., 2010). Moreover, there may exist scope to explore other powder morphologies in future studies.

\subsection{Powder purity}

This can be defined as a level of impurities and porosity in the powders. Impurities can cause nucleation, oxidization (Balla and Bandyopadhyay, 2010) and irregularities in deposited structure (Ferguson et al., 2015). Powder storage environment can also affect purity, particularly during the time when the LENS hopper needs to be filled. Care should be taken to prevent moisture absorption and oxide layer formation, which can impact the predictability of powder melting point (Hebert, 2016). Moreover, after deposition, recover and reuse of unmelted powder may be problematic and the particle size, distribution and oxidation state of the powder cannot be guaranteed and can compromise subsequent builds. Finally, should several different materials be used on the LENS machine, potential cross contamination of powders may become problematic.

Figure 6 (A) Deposition patterns for (a) raster, (b) offset out, (c) offset in and (d) fractal and (B) default deposition pattern on LENS process

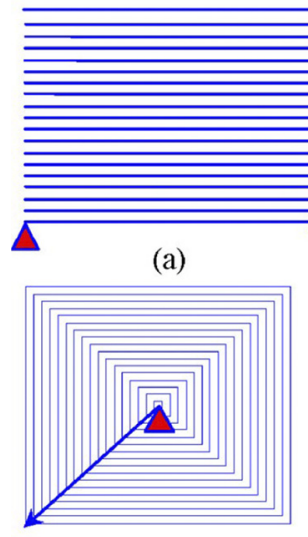

(c)

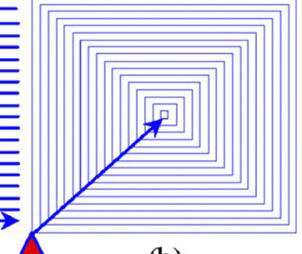

(b)

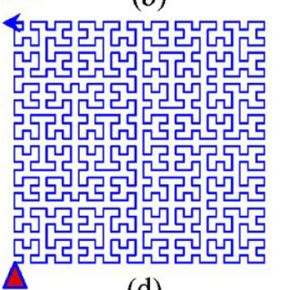

(d)

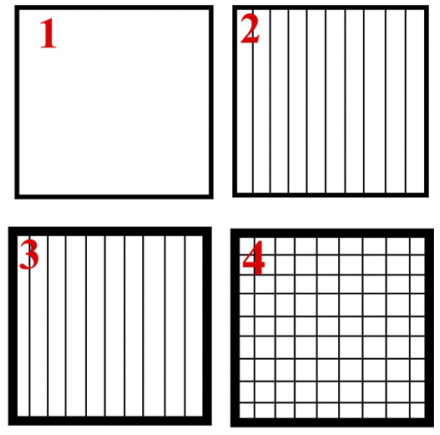

(a)

(b)

Source: Reproduced from Yu et al. (2011) with the permission from Elsevier 


\subsection{Laser absorption}

Laser absorption coefficient of a material is directly proportional to electrical resistance and inversely proportional to the wavelength of laser (Balla et al., 2010a; Espana et al., Balla et al., 2009). The implication of this is that alloys with higher electrical resistance require increased laser power to ensure complete melting during the build process. Additionally, lasers with a shorter wavelength require proportionately more energy to melt a respective powder. The relationship between laser absorption coefficient and electrical resistance can result in partial melting regions during the build process when multiple materials have significantly different electrical resistance. In the multi-material samples of $\mathrm{Ta}$ and $\mathrm{Ti}$ for instance, Ta absorbs less energy compared to Ti, which can lead to unmelted regions during deposition (Balla et al., 2010a). Also, high electrically conducting materials such as Al and $\mathrm{Cu}$ are difficult to fabricate with this method due to their low laser energy absorption coefficients (Balla et al., 2009).

\subsection{Atmosphere}

The LENS process is generally performed in an inert argon environment to avoid issues relating to oxidation of the fabricated parts. Impurities such as oxygen in the build environment during deposition can result in nucleation. This prevents amorphous structure creation and unwanted pores due to the reaction of molten metals with oxygen (Balla and Bandyopadhyay, 2010). There have been suggestions to use an alternative gas like nitrogen as preliminary findings during deposition of titanium-molybdenum and pure titanium have resulted in increases in micro-hardness compared with when argon gas is used (Borkar et al., 2012; Shishkovsky and Smurov, 2012; Mohseni et al., 2015). We speculate that there will be an increased interest by research groups to investigate alternative gaseous build environments and to examine the resulting microstructural changes.

\subsection{Thermal build properties}

In LENS the heat dissipation occurs mostly through the substrate or previously deposited layers unlike PBF processes, which also realizes heat dissipation through the surrounding build powder. The consequence of this is that thermal control can be more difficult to manage and is inherent to the respective thermal characteristics of the selected build platform and processed materials. It has been found in previous studies that the cooling rate can be increased by decreasing the temperature of either the substrate or previous build layer, as can be seen in Figure 7 (Zheng et al., 2008). With respect to LENS there are two feasible methodologies that can allow for control of this parameter. Firstly, the build process could be started with a specified substrate temperature. In the study by Baek et al. (2017) examining the high-speed deposition of tool steel M4 on an AISI D2 substrate, it was found that by increasing the preheating temperature, the hardness increased while the strength and toughness decreases. Moreover, the tensile and impact properties deteriorated rapidly at excessively high preheating temperatures (greater than $500^{\circ} \mathrm{C}$ ). However, in many LENS setups there is no accommodation for pre-heating of the substrate beyond the ambient temperature. Furthermore, we can define a delay interval between layer depositions to allow thermal dissipation until an ideal
Figure 7 A graph illustrating the relationship between cooling rate and substrate/deposited temperature for Ti-6Al-4V deposition

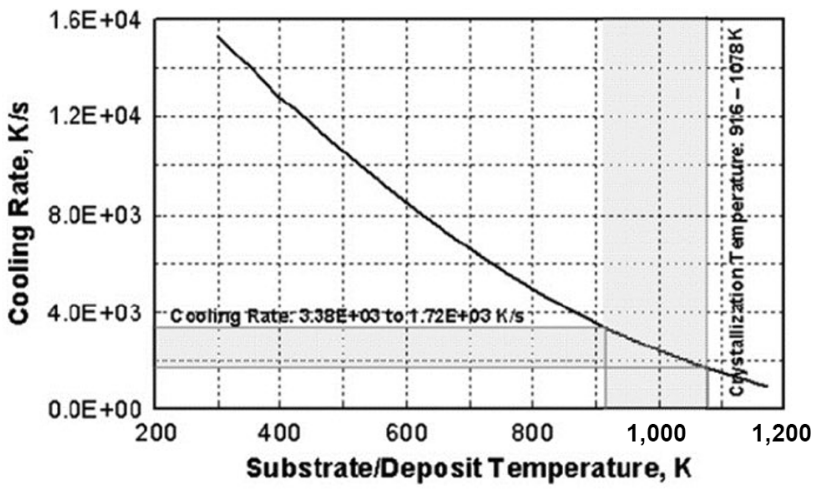

Source: Reproduced from Balla and Bandyopadhyay (2010) wit the permission from Elsevier

temperature is attained. For instance, in the study by Yadollahi et al. (2015), it was found that by increasing the time interval by a factor of nine, a more uniform microstructure and increased microhardness is attainable for stainless steel 316 L. Finally, Mazumder et al. (1999) studied the effect of gas flow rate on cooling rate. They indicated there is no significant influence of changing gas flow rate on cooling rate.

\section{Laser engineered net shaping additive manufacturing outputs}

Despite the significant potential as a metal AM process, LENS has been found to create parts with varying mechanical properties. This has been true even when using the same material, thereby limiting its mainstream popularity as a robust and repeatable build process. In an attempt to shed further light on this situation, we will examine more closely the typical LENS build parameters and outputs, specifically the melt pool, scan geometry and resulting build porosity.

\subsection{Mechanical properties}

As illustrated in previous sections, input parameters have a significant influence on mechanical properties. In fact, there is a complex relationship between the input/output parameters and resulting mechanical properties. Several input parameters can have similar effects on mechanical properties, but some are more influential than others.

One of the main mechanical properties that is very important to understand is residual stress. The main causes of residual stress after DED are the dynamic temperature distribution and cooling/heating rate within the component. These contain high thermal gradients and repetitious/rapid local heat transfer (Saboori et al., 2017). Residual stresses, whose magnitude can exceed the yield strength of the alloy, affect corrosion resistance, fracture toughness, crack growth behavior and fatigue performance (Mukherjee et al., 2017). Increasing laser power could increase the residual stress between layers significantly (Pratt et al., 2008). On the other hand, powder feed rate has an insignificant effect on residual stress (Mukherjee et al., 2017). It is seen that, in Ti-6Al-4V alloy 
there is a correlation between residual stresses within the building plane and the laser scanning direction in which there is a compressive residual stress at the center and tensile stress at the edges of the component (Saboori et al., 2017). In some cases, the residual stress can affect material deposition, particularly for immiscible alloys such as when depositing brass on an AISI 410 substrate (Vandenbroucke and Kruth, 2007). Table 1 illustrates the relationship between input/outputs parameters and mechanical properties.

\subsection{Melt-pool}

The melt-pool is an intermediate output that can be examined during the build process and appears to be the most significant measurable output to determine final LENS part quality. The size of melt-pool itself significantly influences solidification and the resulting layer height consistency. Therefore, it is considered one of the most influential factors relating to the build consistency and ultimately dictates the mechanical properties of the built part. Too large a melt-pool causes deep re-melting of the previously deposited material, affecting product shape and even may cause the top portion of the product to collapse. Conversely, too small a melt-pool can lead to porosity in the structure. For the optimal build, a uniform melt-pool size is required relative to the controllable build parameters, to ensure geometrical repeatability and formation of a high-strength bond between the manufactured layers (Beuth and Klingbeil, 2001).
To better understand melt-pool dimensional effects and relations to input parameters, several thermal transformation simulations have been carried out. Wang et al. (2008) simulated a heat distribution model using SYSWELD software on a single wall deposition of stainless steel 410 to obtain a regular melt-pool size through optimization of laser power. Due to residual temperature during the LENS build process, the melt-pool dimensions were shown to increase. They determined a nominal laser power for each pass during ten layers of deposition to obtain an approximate twodimensional melt-pool size, as illustrated in Figure 8. However, it seems the authors ignored the effect of mass transformation on the melt-pool.

Neela and De (2009) studied thermal behavior of LENS to obtain a constant melt-pool dimension when processing 316 stainless steel by simulating the combined effect of laser power, scan speed and powder flow rate. Figure 9 illustrates the results of their finite element simulation assuming a constant 60 per cent powder capture rate into the melt-pool. As mentioned previously, if the melt-pool dimensions change, the powder capture rate will change accordingly. The authors concluded from this study that the synchronicity of these parameters are vital to avoid over-melting. Additionally, parameters are required to be adjusted dynamically as the build progresses to maintain a uniform layer height. Combining these findings with those in the study by Wang et al., we speculate that the timecorrelated function of the laser power is arguably the most influential parameter for melt-pool consistency.

Table 1 Effect of inputs parameters on outputs parameter and mechanical properties

\begin{tabular}{lll}
\hline Input parameters & Output parameters & Mechanical properties \\
\hline Increasing laser power & Decrease partial melting (Balla et al., 2009) & Reduction on hardness (Wang et al., 2008) \\
& & May increase the part stiffness (Krishna et al., 2007) \\
Increase residual stress (Pratt et al., 2008) & Increase surface roughness (Zhai et al., 2016) & Less ductility (Pegues et al., 2017)
\end{tabular}
et al., 2010; Kobryn et al., 2000; Krishna et al., 2007; Lewis and Schlienger, 2000)

Increase porosity (Pegues et al., 2017)

Higher cooling rate (Kobryn et al., 2000)

Feed rate decreases

Thinner layer (Kummailil et al., 2005)

Reduction in part stiffness (Kummailil et al., 2005)

Create a mask region surrounding melt-pool (Paul et al., 2006)

Hatch distance

Porosity volume increases (Krishna et al., 2007)

Reduction in part stiffness (Krishna et al., 2007)

increases

Positive focal distance

Preheated powder particles (Sharman et al., 2018)

Reduction in cooling rate (Sharman et al., 2018)

Affect built geometry (Xiong et al., 2009)

Negative focal distance

Affect built geometry (Xiong et al., 2009)

Deposition pattern

Affect build geometry (Wang et al., 2018)

Part distortion (Yu et al., 2011)

Finer powder

Powder purity

Less heat required (Balla and Bandyopadhyay, 2010)

Irregularities in build structure (Ferguson et al., 2015)

Nucleation and oxidation (Balla and Bandyopadhyay, 2010)

Laser absorption

Partial melting regions (Balla et al., 2010a)

Atmosphere

Nucleation (Balla and Bandyopadhyay, 2010)

May result in crack free deposition (Sharman et al., 2018)

May result in a cracked deposition (Sharman et al., 2018)

Affect residual stress (Nickel et al., 2001)

Affect tensile strength (Yu et al., 2011)

No studies found

No studies found

No studies found

Affect micro-hardness (Borkar et al., 2012; Shishkovsky and Smurov, 2012; Mohseni et al., 2015) 
Figure 8 (a) Nominal laser powers for each layer to have a uniform size of melt-pool and (b) melt-pool shapes and sizes when the laser beam is in the center of a thin wall for different layers. The average size of the melt-pool is $2.0 \mathrm{~mm}$

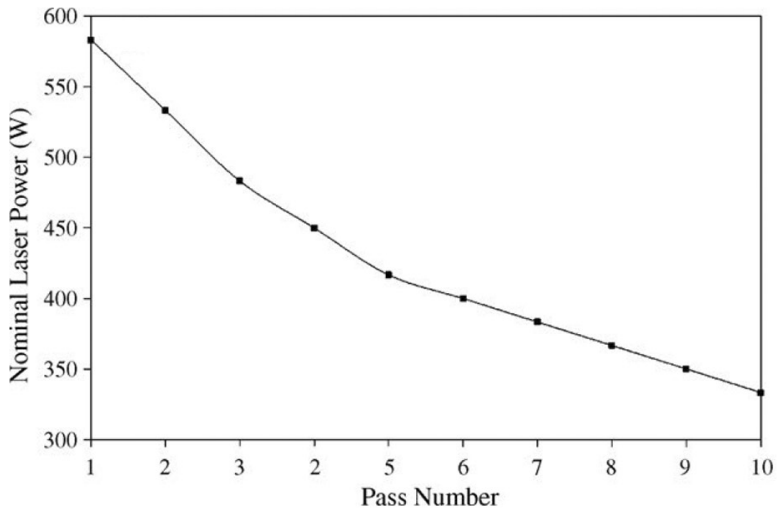

(a)

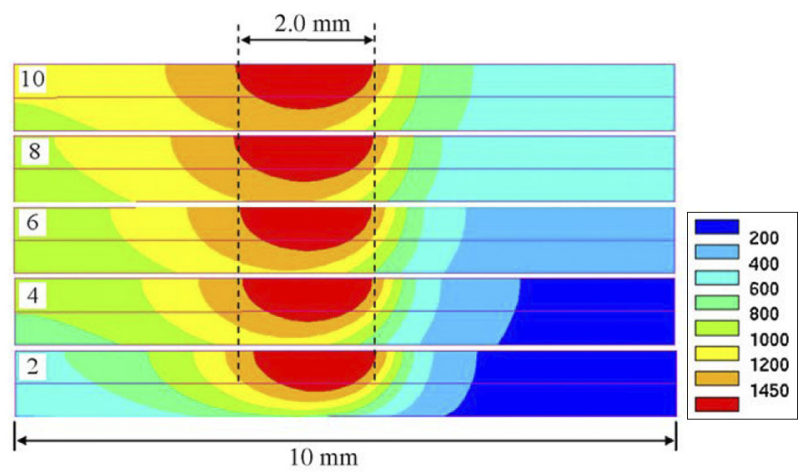

(b)

Notes: The average size of the melt-pool is $2.0 \mathrm{~mm}$. The melt-pool size is based on the melting temperature of SS410 $\left(1,450^{\circ} \mathrm{C}\right)$

Source: Reproduced from Wang et al. (2008) with permission from Elsevier

Figure 9 A graph illustrating the combined relationship between laser power, scan speed and powder mass flow rate based on a steady meltpool size for SS316

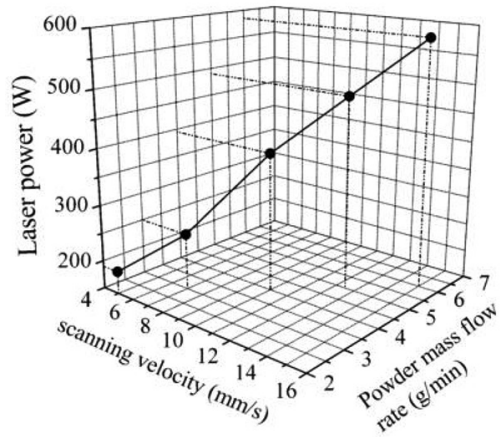

Source: Reproduced from Wang et al. (2008) with permission from Elsevier

In another study, Qi et al. (2006) worked on a mathematical model to predict length and width of the melt-pool. The model predicted that the length and width are directly proportional to the laser power. However, the model's calculated length and width were greater than the deposited samples by 22 per cent. The authors assumed that the difference between the simulated material properties of the model and the process were the cause of mismatch between the calculated and actual values.

As a part of a comprehensive mathematical model, done by Han et al. (2004) the effects of laser power, scan speed and powder feed rate were studied on the melt-pool length and the peak temperature. It was found that while the melt-pool dimensions and peak temperature reduce by increasing the powder feed rate and scan speed, they grow by increasing the laser power. The effect of scan speed was explained by the interaction time between the laser and the powder, that is, the material decreases when the scan speed is increased. In terms of the powder feed rate, it was believed that the increasing feed rate can intensify the power attenuation and eventually reduce the melt-pool temperatures and lengths.

Han et al. (2005) studied a simulation to predict the meltpool length and peak temperature during the deposition of a line. The results showed that while the actual melt-pool lengths fluctuate more than the calculated ones, the error between the mean theoretical and experimental length is only 6-7 per cent. The fluctuation was explained by the delivery of the powder feed during the process. Regarding the peak temperature, the simulated values were greater by $100-250 \mathrm{~K}$, as the material absorption coefficient is assumed to be constant. The material absorption coefficient may be poorly estimated due to the differences in the temperature of the melt-pool.

Another approach has been to predict trends in the solidification microstructure using melt-pool behavior. Bontha et al. (2006) developed dimensionless process maps for thermal gradient and solidification cooling rate for a thin-wall Ti-6Al-4V structure using a two-dimensional moving heat source Rosenthal solution, as illustrated in Figure 10. The authors analytically extracted thermal gradient and cooling rates throughout the deposition process variables and computed resulting melt-pool depth. However, to do so several assumptions were required. Firstly, wall thickness $(b)$ is much less than the height $(h)$ and length $(\mathrm{L})$, hence, heat conduction is restricted to the $X-Z$ plane. Secondly, it is assumed that $\mathrm{L}$ and $\mathrm{h}$ are sufficiently large such that the steady-state two-dimensional Rosenthal solution for a point heat source traversing an infinite half-space applies. Thirdly, the relative coordinates $\left(X_{0}, Z_{0}\right)$ in Figure 10 are related to fixed spatial coordinates $(\mathrm{X}, Z)$ at any time $(t)$ as $\left(X_{0}, Z_{0}\right)=(\mathrm{X}$ $\mathrm{vT}, \mathrm{Z})$, where $v$ is the laser velocity $\left(\bar{Z}_{0} / \bar{Z}_{m}\right)$.

They came up with several expressions for dimensionless cooling rate, dimensionless thermal gradient and melting point temperature. The expression for the dimensionless cooling rate $\partial \bar{T} / \partial \bar{t}$ was determined to be: 
Figure 10 Schematic of thin wall

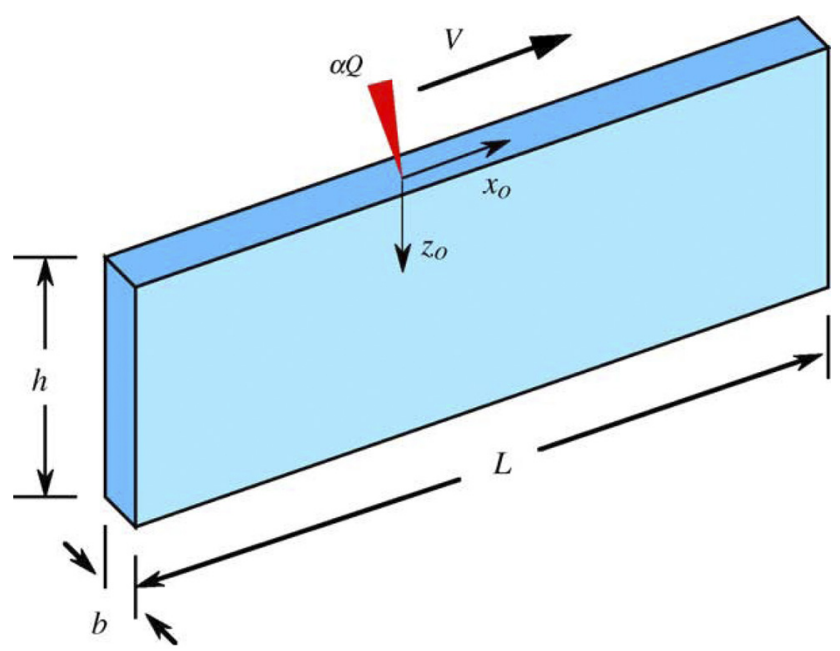

Source: Reproduced from Bontha et al. (2006) with the permission from Elsevier

$$
\begin{aligned}
& \frac{\partial \bar{T}}{\partial \bar{t}}=e^{-(\bar{x}-\bar{t})}\left\{\frac{(\bar{x}-\bar{t})}{\sqrt{\left(\bar{x}-\bar{t}^{2}+\bar{z}_{0}^{2}\right.}} K_{1}\left(\sqrt{(\bar{x}-\bar{t})^{2}+\bar{z}_{0}^{2}}\right)\right. \\
& \left.\quad+K_{0}\left(\sqrt{(\bar{x}-\bar{t})^{2}+\bar{z}_{0}^{2}}\right)\right\}
\end{aligned}
$$

where $|\overline{\nabla T}|$ is the dimensionless thermal gradient, and can be determined by:
Volume $26 \cdot$ Number $6 \cdot 2020 \cdot 1059-1078$

$$
|\overline{\nabla T}|=\left(\frac{2 \pi b k^{2}}{\alpha Q \rho c V}\right)|\nabla T|
$$

and

$$
\bar{T}_{m}
$$

is the dimensionless normalized melting temperature and is determined by:

$$
\bar{T}_{m}=\frac{T_{m}-T_{0}}{\alpha Q / \pi k b}
$$

Here $T_{0}$ is the reference temperature, $\alpha Q$ the absorbed laser power, $V$ the velocity, $\mathrm{b}$ the wall thickness, $\mathrm{L}$ the length, $\left(X_{0}\right.$, $Z_{0}$ ) the relative coordinates, $t$ the time, $K_{0}$ is the modified Bessel function, $\mathrm{T}$ is the temperature at a location, $\left(X_{0}, Z_{0}\right)$ the thermophysical properties and $\rho, \mathrm{c}$ and $\mathrm{k}$ are the density, specific heat and thermal conductivity of the material, respectively.

By using these expressions, they plotted dimensionless process maps to anticipate microstructure. These process maps could be used for any material system by modifying input thermophysical properties $\rho, c, k$ and $T_{m}$.

Figure 11(a) provides useful information about the relationship between the depth of melt-pool, normalized melting temperature and cooling rate. It shows cooling rate reduces significantly from the top of the surface $\left(\bar{Z}_{0} / \bar{Z}_{m}=0\right)$ to bottom of the melt-pool $\left(\bar{Z}_{0} / \bar{Z}_{m}=1\right)$ particularly when $\bar{T}_{m}$ is high (low laser power). Conversely, Figure 11(b) provides information about relation between thermal gradient, meltpool depth and normalized melting temperature. It shows the

Figure 11 Process maps of (a) cooling rate and (b) thermal gradient $\left(\bar{Z}_{0} / \bar{Z}_{m}\right)$

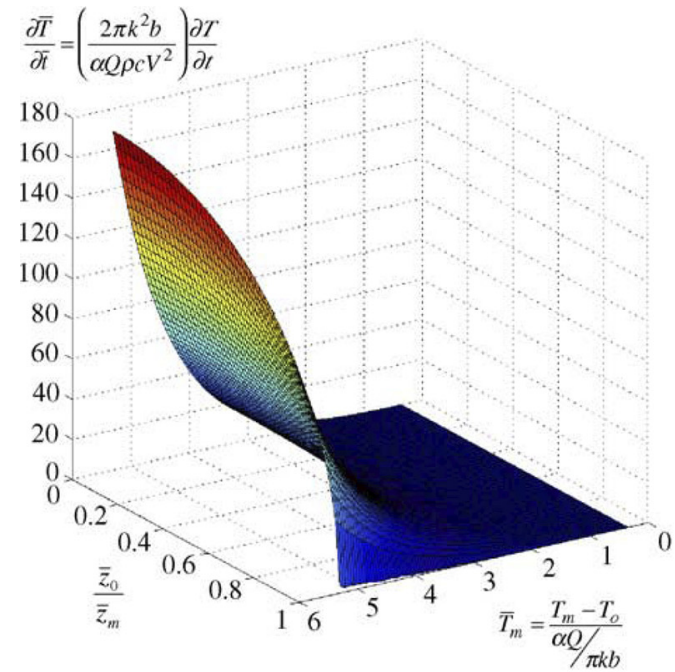

(a)

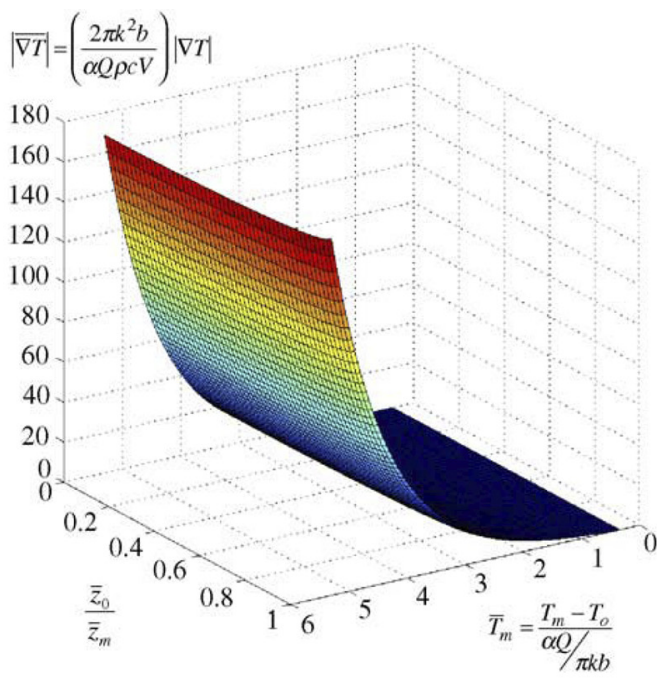

(b)

Source: Reproduced from Bontha et al. (2006) with the permission from Elsevier 
depth of melt-pool does not affect the thermal gradient and also that by increasing the normalized melting temperature, the thermal gradient increases.

Studies were also performed to examine the effect of thermal gradient and cooling rate on solidification. Where $G=[\nabla T]$ and the expression of solidification $\mathrm{R}$, determined as;

$$
\mathrm{R}=\frac{1}{\mathrm{G}} \frac{\partial \mathrm{T} \Delta}{\partial \mathrm{t}}
$$

In the same study, they examined the effect of scan speed and laser power on grain morphology with respect to the parameters G and R. Solidification maps for Ti-Al6-V4 were determined for variations in laser power and scan speed, as illustrated in Figure 12. It was found that by increasing the laser power, while maintaining a constant scan speed, the thermal gradient decreases and the microstructure changes from fully columnar to mixed columnar and equiaxed. Furthermore, for increased build height, the solidification decreases in most cases. Conversely, it was found that for increased scan speed, while maintaining a constant laser power, the thermal gradient and solidification increases, while the microstructure changes from fully columnar to mixed columnar and equiaxed (Bontha et al., 2006). These findings once again highlight the critical nature of the build parameter synchronicity in controlling the melt-pool dynamics.

In recent years, Optomec (Albuquerque and US) has introduced a new melt-pool sensor for their LENS machines. The sensor monitors the deposition process and control software automatically adjusts laser power to maintain a constant size of melt-pool. This level of melt-pool process control vastly improves uniformity in micro-structure and geometry (Grylls, 2013). In addition, there is a dualwavelength pyrometer that can measure temperature during the process. Marshall et al. (2016) provided a pyrometer data article showing temperature response of Ti-6Al-4V of a thin wall structure during deposition. The authors stated this information could be used for understanding heat transfer, cooling rate, melt-pool stability and other influential dynamics. However, they did not perform any analysis on the data.

\subsection{Scan geometry}

Scan geometry is found to influence the part layer thickness in LENS, making it a critical build parameter. Kobryn et al. (2000) attempted to find a relationship between the build height of a scan line, scan speed and laser power for a thin and thick build substrate. It was observed that thin substrates have a greater initial build layer height compared to thick substrates due to heat dissipation factors within the build plate. Conversely, increasing scan speed leads to a thinner scan line where it seems, there was no clear relationship between substrate and layer thicknesses.

The effects of laser power, powder feed rate, scan speed and hatch distance have also been assessed by measuring the scan line height (Figures 13(A) and 13(B)) and a mathematical equation for prediction of the height was offered by Kummailil et al. (2005). It was found that while the built height is inversely proportional to scan speed and hatch distance, it is directly proportional to laser power and powder feed rate. It was concluded that the feed rate and scan speed have a higher impact on the build height as opposed to the laser power and hatch distance.

Kummailil et al. also proposed a mathematical model [Equation (5)] for the effect of mentioned parameters on the height:

$$
H \propto\left(\frac{p A m}{H D \times u}\right)^{a}
$$

where $H$ is the height, $P$ is laser power, $A$ is absorptivity of powder, $m$ is feed rate, HD is hatch distance, $u$ is scan speed and $a$ is the correlation coefficient.

Manvatkar et al. (2011) attempted to estimate the dimension of the scan line by calculating the input heat and also heat

Figure 12 G vs R plots, (a) effect of laser power and (b) effect of scan speed

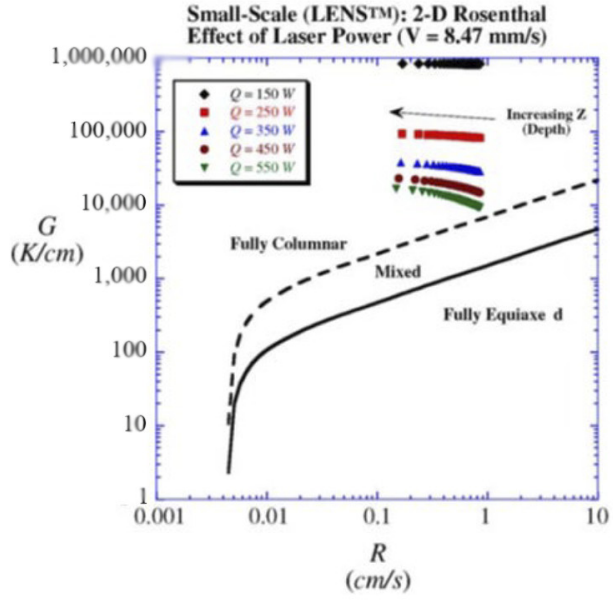

(a)

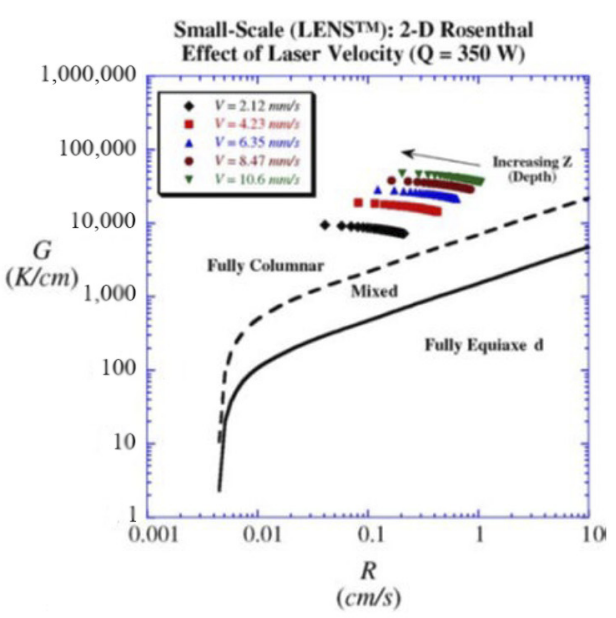

(b)

Source: Reproduced from Bontha et al. (2006) with the permission from Elsevier 
Figure 13 (A) Images illustrating the influence of different laser power and scan speed on the build height of a single track at (a) $200 \mathrm{~W}, 6 \mathrm{~mm} / \mathrm{s}, 6.3 \mathrm{~g} / \mathrm{min}$; (b) $250 \mathrm{~W}, 8 \mathrm{~mm} / \mathrm{s}, 6.3 \mathrm{~g} / \mathrm{min}$ and (c) $300 \mathrm{~W}, 4 \mathrm{~mm} / \mathrm{s}, 6.3 \mathrm{~g} / \mathrm{min}$ and (B) images illustrating the influence of different powder feed rate on the build height of a single track at (a) $300 \mathrm{~W}, 6 \mathrm{~mm} / \mathrm{s}, 7.8 \mathrm{~g} / \mathrm{min}$; (b) $200 \mathrm{~W}, 4 \mathrm{~mm} / \mathrm{s}, 8.8 \mathrm{~g} / \mathrm{min}$ and (c) $300 \mathrm{~W}, 6 \mathrm{~mm} / \mathrm{s}, 9.8 \mathrm{~g} / \mathrm{min}$

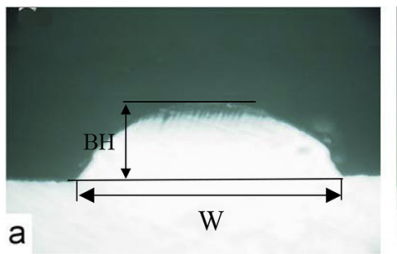

b

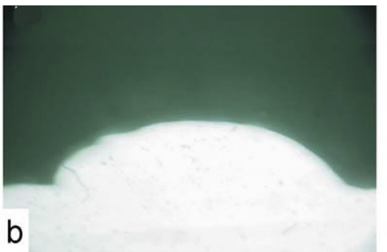

(a)
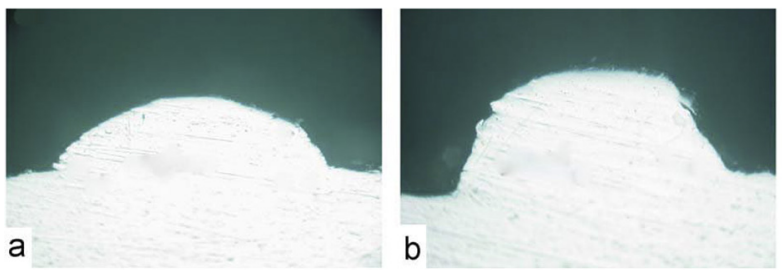

(b)
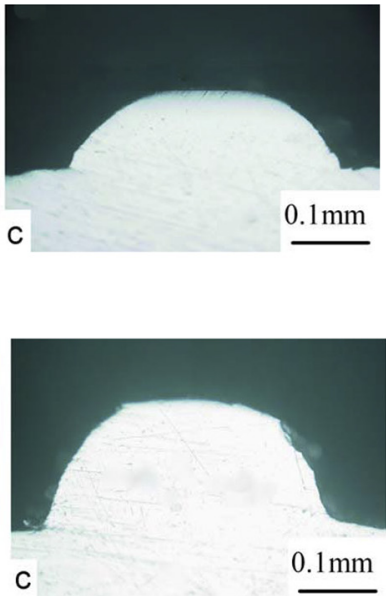

$0.1 \mathrm{~mm}$

Source: Reproduced from Lu et al. (2010) with the permission from Elsevier

transfer for the deposited layers. It was found that the geometry of the scan line could be estimated by finding the solidification profile. Equation (6) was used to calculate the height for $x, y \leq$ $r_{e f f}^{z} ; z \leq h$

$$
q_{v}=\frac{\eta P d}{\pi\left(r_{\text {eff }}^{z}\right)^{2} h} \exp \left[-d\left(\frac{x^{2}}{\left(r_{\text {eff }}^{z}\right)^{2}}+\frac{y^{2}}{\left(r_{\text {eff }}^{z}\right)^{2}}+\frac{z^{2}}{h^{2}}\right)\right]
$$

where $q_{v}$ is the volumetric heat input, $\eta$ is the absorption coefficient, $P$ is the laser power, $d$ is the beam distribution, $r_{e f f}^{z}$ is the effective radius of laser at the height $z, h$ is the layer height and $x, y, z$ are the coordinates of the spot. Understanding of scan geometry could be very beneficial to achieve better part accuracy of the desired parts.

In addition to the build dynamics of a single scan line, Izadi et al. (2017) studied the effect of process parameters on the construction of cylindrical structures of stainless steel $316 \mathrm{~L}$. Interrogation parameters were based on Taguchi design of experiment and validated against previously derived equations for the energy density in powder based systems (Vandenbroucke and Kruth, 2007; Di et al., 2012; Gu et al., 2013; Jia and $\mathrm{Gu}, 2014)$. It was discovered that the geometry of the printed samples varied from one another, resulting in dramatic fluctuations of the observed sample diameter and height (Figure 14). In several instances samples were found to contain a concave form at the upper surface of the cylinder, resulting in several depth variations from what was anticipated. Ultimately, these defects resulted from under deposition of material, which resulted in the part porosity changing from bottom to top. The authors concluded that current mathematical models for the energy density were not sufficient to accurately model DED based build processes and new models require development.

The build height of a deposited line was predicted by a mathematical model and compared with the experimental samples by Qi et al. (2006). The model could prove that, as shown in Figure 15, the height is increased by laser power. This increase is linear except at low power, less than $400 \mathrm{~W}$. The difference between the actual sample height and calculated value was up to 32 per cent, the authors' assumed this was due to the difference between the theoretical and actual powder concentration distribution and powder capture.

Similarly, He and Mazumder (2007) worked on a threedimentional model to calculate the build height of a deposited single crack when the laser power, scan speed and powder feed rate are changed. The model could successfully predict that the build height is increased by increasing the laser power and decreasing the scan speed. However, the accuracy of the model decreased at higher power as the specific heat and thermal

Figure 14 L9 orthogonal matrix of Taguchi design of experiment

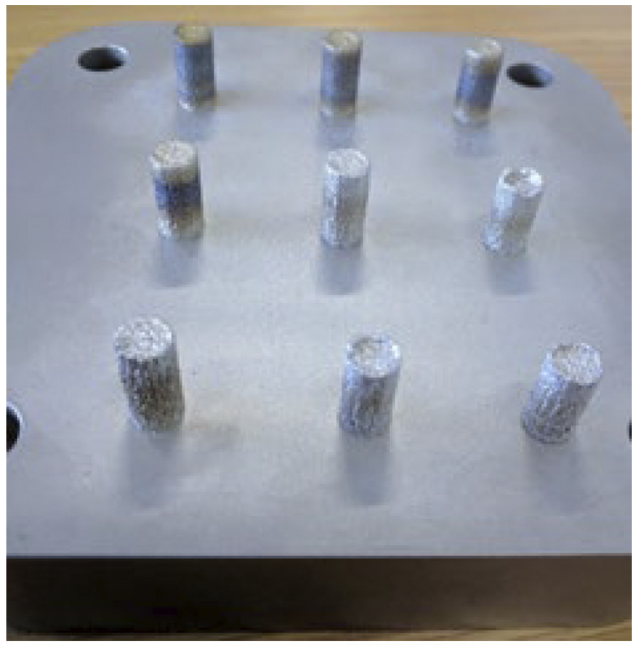

Source: Izadi et al. (2017) 
Figure 15 Predicted and experimental samples build height comparison

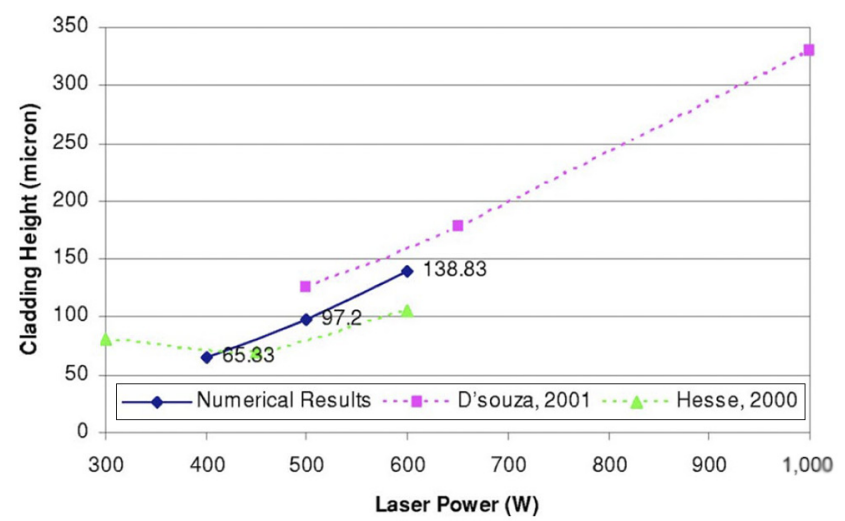

Source: Reproduced from Qi et al. (2006) with the permission from Elsevier

conductivity were assumed to be constant and the actual powder distribution may be different. The models used in both studies were used for only a single deposited line. More work is needed to analyze multiple layer samples.

Katinas et al. (2018) worked on a simulation predicting the powder capture rate and eventually the dimensions of the deposited line and melt-pool geometry. The results showed a reasonable correlation between the simulated values and two deposited lines done in the experiment. The track width and height errors were 2 and 3 per cent, respectively.

\subsection{Porosity}

Structural porosity is another important consequence of LENS that can significantly influence both the mechanical properties and the quality of products. In the majority of cases, porosity is perceived as a defect due to a reduction in mechanical properties. For instance, Razavi et al. (2018) performed a comparison study between a porous and non-porous, part built using LENS with different process parameters. He found the fatigue strengths of non-porous samples to be almost four times higher than porous samples. However, they did not study the exact effect of each process parameter on fatigue strength. In some instances engineers can take advantage of the inherent porosity, specifically in medical applications (Sun et al., 2015; Das et al., 2013; Parthasarathy et al., 2011), where there are two important benefits to porous structures. Firstly, the porous structure can decrease the stiffness mismatch between implants and bone tissue, minimizing stress shielding effects. Secondly, porous implants can result in osseointegration, with living cells growing into open pores to provide mechanical locking and assist long-term fixation (Xue et al., 2007).

There are several demonstrated examples of porous structures using LENS, including:

- Partial fusion porosity: This results from insufficient/ incomplete melting between or along layer boundaries. As this process is chaotic, there is no well-defined pore shape (Krishna et al., 2007).

- Gas porosity: This results from gas entrapment in the feed powder, which expands during laser melting. This leads to very low porosity, characterized by spherical bubbles (Kobryn et al., 2000).

- Hatch distance porosity: Resulting from pore connectivity and can be controlled by altering the hatch distance; with increased distances resulting in higher porosity (Krishna et al., 2007; Kummailil et al., 2005).

Despite these methods of introducing porosity within the build process, production of accurate porous structures still remains challenging due to the complexity of thermal control in LENS. Given the limited number of studies in this area, particularly for industrial applications, LENS based porous structures warrant further investigation.

\section{Discussion and conclusion}

LENS AM is an emerging technology with significant potential for the fabrication of metallic parts, with several potential advantages over more common powder bed technologies, particularly with regards to the formation of functionally graded and larger components. It has been discovered that process parameters, their synchronicity and optimization, play a vital part in the effectiveness of LENS, and significant work remains to create a robust framework for production with a high degree of repeatability.

With respect to critical parameters, there are several controllable and inherent variables, all of which impact the final build quality. Of these, laser power, powder feed rate, scan speed and hatch distance appear to be the most influential and have been the primary focus of the limited number of current studies of this technology. Drawing parallels with PBF processes, researchers have found a relationship between energy density, macro-structure and mechanical properties (Vandenbroucke and Kruth, 2007; Di et al., 2012; Gu et al., 2013; Jia and $\mathrm{Gu}, 2014$ ), where the energy input is proportional to the laser power, scan speed, hatch distance and layer thickness. Researchers of the LENS build process have tried to derive similar examples of the energy density equation. However, they have been largely unsuccessful due to the instabilities in the layer thickness of manufactured parts. This is believed to be because the layer thickness depends highly on powder capture rate, which, in turn, dictates the melt-pool's dimensions. As the melt-pool dimensions have a strong relationship with process temperature, thermal control and its associated parameters, it is critical to establish a similar mathematical relationship for energy density in the LENS process.

Ultimately our findings reveal there is significant scope for research to improve the build process and address issues such as, deposited part precision, micro-structure quality and part porosity, which hinder LENS becoming an AM standard. We conclude future studies should focus upon:

- The effect of the parameters on final geometrical accuracy.

- Examination of a wider range of build parameters, as current studies have only examined laser powers between 150-400W, scan speeds of 6-12 $\mathrm{mm} / \mathrm{min}$ and powder feed rates of 5-10 gram $/ \mathrm{min}$.

- Development of robust mathematical models reflecting the build process. 
- Investigating multiple material depositions in a single build.

- Investigation of alternative scan patterns.

- More precisely understanding the interrelationship between the various process parameters with and across to a wider variety of material.

- Developing an algorithm to control parameters such as powder feed rate and scan speed in real-time.

- Studying the effect of post-processing on the deposited part to improve mechanical properties and eliminate residual stress.

- Investigating the uniformity of microstructure and macrostructure in a deposited part from bottom to top.

\section{References}

Akman, E., Demir, A., Canel, T. and Sinmazçelik, T. (2009), "Laser welding of Ti6Al4V titanium alloys", fournal of Materials Processing Technology, Vol. 209 No. 8, pp. 3705-3713.

Amine, T., Newkirk, J. and Liou, F. (2014), "An investigation of the effect of laser deposition parameters on characteristics of multilayered $316 \mathrm{~L}$ deposits", The International fournal of Advanced Manufacturing Technology, Vol. 73 Nos 9/12, pp. 1739-1749.

Baek, G.Y., Lee, K.Y., Park, S.H. and Shim, D.S. (2017), "Effects of substrate preheating during direct energy deposition on microstructure, hardness, tensile strength, and notch toughness", Metals and Materials International, Vol. 23 No. 6, pp. 1204-1215.

Balla, V.K. and Bandyopadhyay, A. (2010), "Laser processing of Fe-based bulk amorphous alloy", Surface and Coatings Technology, Vol. 205 No. 7, pp. 2661-2667.

Balla, V.K., Banerjee, S., Bose, S. and Bandyopadhyay, A. (2010a), "Direct laser processing of a tantalum coating on titanium for bone replacement structures", ACTA Biomaterialia, Vol. 6 No. 6, pp. 2329-2334.

Balla, V.K., Bodhak, S., Bose, S. and Bandyopadhyay, A. (2010b), "Porous tantalum structures for bone implants: fabrication, mechanical and in vitro biological properties", ACTA Biomaterialia, Vol. 6 No. 8, p. 3349.

Balla, V., DeVasConCellos, P., Xue, W., Bose, S. and Bandyopadhyay, A. (2009), "Fabrication of compositionally and structurally graded $\mathrm{Ti}-\mathrm{TiO} 2$ structures using laser engineered net shaping (LENS)", ACTA Biomaterialia, Vol. 5 No. 5, pp. 1831-1837.

Bandyopadhyay, A., Espana, F., Balla, V.K., Bose, S., Ohgami, Y. and Davies, N.M. (2010), "Influence of porosity on mechanical properties and in vivo response of Ti6Al4V implants", ACTA Biomaterialia, Vol. 6 No. 4, pp. 1640-1648.

Benyounis, K.Y., Olabi, A.G. and Hashmi, M.S.J. (2005), "Effect of laser welding parameters on the heat input and weld-bead profile", fournal of Materials Processing Technology, Vols 164/165, pp. 978-985.

Beuth, J. and Klingbeil, N. (2001), "The role of process variables in laser-based direct metal solid freeform fabrication", fOM, Vol. 53 No. 9, pp. 36-39.
Bontha, S., Klingbeil, N.W., Kobryn, P.A. and Fraser, H.L. (2006), "Thermal process maps for predicting solidification microstructure in laser fabrication of thin-wall structures", fournal of Materials Processing Technology, Vol. 178 Nos 1/3, pp. 135-142.

Borkar, T., Gopagoni, S., Nag, S., Hwang, J., Collins, P. and Banerjee, R. r.b.u.e. (2012), "In situ nitridation of titaniummolybdenum alloys during laser deposition", fournal of Materials Science, Vol. 47 No. 20, pp. 7157-7166.

Camacho, D.D., Clayton, P., O'Brien, W., Ferron, R., Juenger, M., Salamone, S. and Seepersad, C. (2017), "Applications of additive manufacturing in the construction industry - a prospective review", ISARC. Proceedings of the International Symposium on Automation and Robotics in Construction, Vol. 34, Vilnius Gediminas Technical University, Department of Construction Economics \& Property.

Campbell, I., Bourell, D. and Gibson, I. (2012), "Additive manufacturing: rapid prototyping comes of age", Rapid Prototyping fournal, Vol. 18 No. 4, pp. 255-258.

Chen, R.K., Jin, Y-A., Wensman, J. and Shih, A. (2016), "Additive manufacturing of custom orthoses and prostheses a review", Additive Manufacturing, Vol. 12, pp. 77-89.

Dai, K. and Shaw, L. (2002), "Distortion minimization of laser-processed components through control of laser scanning patterns", Rapid Prototyping fournal, Vol. 8 No. 5, pp. 270-276.

Das, M., Balla, V., Kumar, T. and Manna, I. (2013), "Fabrication of biomedical implants using Laser Engineered Net Shaping (LENS ${ }^{\mathrm{TM}}$ )", Transactions of the Indian Ceramic Society, Vol. 72 No. 3, pp. 169-174.

Di, W., Yongqiang, Y., Xubin, S. and Yonghua, C. (2012), "Study on energy input and its influences on single-track, multi-track, and multi-layer in SLM", The International Fournal of Advanced Manufacturing Technology, Vol. 58 Nos 9/ 12, pp. 1189-1199.

Dinda, G., Song, L. and Mazumder, J.J.M. (2008), "Fabrication of Ti-6Al-4V scaffolds by direct metal deposition", Metallurgical and Materials Transactions A, Vol. 39 No. 12, pp. 2914-2922.

Durejko, T., Ziętala, M., Łazińska, M., Lipiński, S., Polkowski, W., Czujko, T. and Varin, R.A. (2016), "Structure and properties of the Fe3Al-type intermetallic alloy fabricated by laser engineered net shaping (LENS)", Materials Science and Engineering: $A$, Vol. 650, pp. 374-381.

Dutta, B. and Froes, F.H. (2015), "The additive manufacturing (AM) of titanium alloys", Titanium Powder Metallurgy, pp. 447-468.

Dutta, B. and Froes, F.H. (2017), "The Additive Manufacturing (AM) of titanium alloys", Metal Powder Report, Vol. 72 No. 2, pp. 96-106.

Espana, F.A., Balla, V.K. and Bandyopadhyay, A. (2010), "Laser surface modification of AISI 410 stainless steel with brass for enhanced thermal properties", Surface and Coatings Technology, Vol. 204 No. 15, pp. 2510-2517.

Espana, F.A., Balla, V.K., Bose, S. and Bandyopadhyay, A. (2010), "Design and fabrication of CoCrMo alloy based novel structures for load bearing implants using laser engineered net shaping", Materials Science and Engineeringm: C, Vol. 30 No. 1, pp. 50-57. 
Ferguson, J.B., Schultz, B.F., Moghadam, A.D. and Rohatgi, P.K. (2015), "Semi-empirical model of deposit size and porosity in 420 stainless steel and 4140 steel using laser engineered net shaping", fournal oF Manufacturing Processes, Vol. 19, pp. 163-170.

Fitzpatrick, A.P., Mohanned, M.I., Collins, P.K. and Gibson, I. (2017), "Design of a patient specific, 3D printed arm cast”, KNE Engineering, Vol. 2 No. 2, pp. 135-142.

Frazier, W.E. (2014), "Metal additive manufacturing: a review", fournal of Materials Engineering and Performance, Vol. 23 No. 6, pp. 1917-1928.

Gedda, H., Powell, J., Wahlström, G., Li, W.-B., Engström, H. and Magnusson, C. (2002), "Energy redistribution during CO 2 laser cladding”, fournal of Laser Applications, Vol. 14 No. 2, pp. 78-82.

German, R.M. (1992), "Prediction of sintered density for bimodal powder mixtures", Metallurgical Transactions A, Vol. 23 No. 5, pp. 1455-1465.

Gibson, I., Rosen, D.W. and Stucker, B. (2010), Additive Manufacturing Technologies, Springer.

Grylls, R. (2013), "Process variable monitoring - how low can you go?”, available at: www.optomec.com/process-variablemonitoring-how-low-can-you-go/

Gu, D.D., Meiners, W., Wissenbach, K. and Poprawe, R. (2012), "Laser additive manufacturing of metallic components: materials, processes and mechanisms", International Materials Reviews, Vol. 57 No. 3, pp. 133-164.

Gu, H., Gong, H., Pal, D., Rafi, K., Starr, T. and Stucker, B. (2013), "Influences of energy density on porosity and microstructure of selective laser melted 17-4PH stainless steel”, 2013 Solid Freeform Fabrication Symposium, p. 474.

Guo, N. and Leu, M.C. (2013), "Additive manufacturing: technology, applications and research needs", Frontiers of Mechanical Engineering, Vol. 8 No. 3, pp. 215-243.

Gurrappa, I. (2003), "Characterization of titanium alloy Ti$6 \mathrm{Al}-4 \mathrm{~V}$ for chemical, marine and industrial applications", Materials Characterization, Vol. 51 Nos 2/3, pp. 131-139. no

Haley, J.C., Schoenung, J.M. and Lavernia, E.J. (2018), "Observations of particle-melt pool impact events in directed energy deposition", Additive Manufacturing, Vol. 22, pp. 368-374.

Han, L., Phatak, K.M. and Liou, F.W. (2005), "Modeling of laser deposition and repair process", Fournal of Laser Applications, Vol. 17 No. 2, pp. 89-99.

Han, L., Phatak, K.M. and Liou, F.W. (2004), "Modeling of laser cladding with powder injection", Metallurgical and Materials Transactions B, Vol. 35 No. 6, pp. 1139-1150.

He, X. and Mazumder, J. (2007), "Transport phenomena during direct metal deposition", Fournal of Applied Physics, Vol. 101 No. 5.

Hebert, R.J. (2016), "Viewpoint: metallurgical aspects of powder bed metal additive manufacturing", fournal of Materials Science, Vol. 51 No. 3, pp. 1165-1175.

Herzog, D., Seyda, V., Wycisk, E. and Emmelmann, C. (2016), "Additive manufacturing of metals", Acta Materialia, Vol. 117, pp. 371-392.

Hofmeister, W. and Griffith, M. (2001), "Solidification in direct metal deposition by LENS processing", fOM, Vol. 53 No. 9, pp. 30-34.
Izadi, M., Farzaneh, A., Gibson, I. and Rolfe, B. (2017), "The effect of process parameters and mechanical properties of direct energy deposited stainless steel 316", Proceedings of the 28th Annual International Solid Freeform Fabrication Symposium, International Symposium - Additive Manufacturing conference, pp. 1058-1067.

Izadi, M., Farzaneh, A., Gibson, I. and Rolfe, B. (2017), "The effect of process parameters and mechanical properties of direct energy deposited stainless steel 316", Solid Freeform Fabrication, pp. 1059-1067.

Jia, Q. and Gu, D. (2014), "Selective laser melting additive manufacturing of Inconel 718 superalloy parts: densification, microstructure and properties", fournal of Alloys and Compounds, Vol. 585, pp. 713-721.

Joseph, J., Hodgson, P., Jarvis, T., Wu, X., Stanford, N. and Fabijanic, D.M. (2018), "Effect of hot isostatic pressing on the microstructure and mechanical properties of additive manufactured AlxCoCrFeNi high entropy alloys", Materials Science and Engineering: A, Vol. 733, pp. 59-70.

Kaji, F. and Barari, A. (2015), "Evaluation of the surface roughness of additive manufacturing parts based on the modelling of cusp geometry", IFAC-PapersOnLine, Vol. 48 No. 3, pp. 658-663.

Kao, Y.-F., Chen, T.-J., Chen, S.-K. and Yeh, J.-W. (2009), "Microstructure and mechanical property of as-cast, -homogenized, and -deformed AlxCoCrFeNi $(0 \leq \mathrm{x} \leq 2)$ highentropy alloys", fournal of Alloys and Compounds, Vol. 488 No. 1, pp. 57-64.

Katinas, C., Shang, W., Shin, Y.C. and Chen, J. (2018), "Modeling particle spray and capture efficiency for direct laser deposition using a four nozzle powder injection system", Fournal of Manufacturing Science and Engineering, Vol. 140 No. 4.

Keicher, D.M. and Miller, W.D. (2001), Multiple Beams and Nozzles to Increase Deposition Rate, Google Patents.

Khairallah, S.A., Anderson, A.T., Rubenchik, A. and King, W.E. (2016), "Laser powder-bed fusion additive manufacturing: physics of complex melt flow and formation mechanisms of pores, spatter, and denudation zones", ACTA Materialia, Vol. 108, pp. 36-45.

King, W.E., Anderson, A.T., Ferencz, R.M., Hodge, N.E., Kamath, C., Khairallah, S.A. and Rubenchik, A.M. (2015), "Laser powder bed fusion additive manufacturing of metals; physics, computational, and materials challenges", Applied Physics Reviews, Vol. 2 No. 4, p. 041304.

Kobryn, P.A., Moore, E.H. and Semiatin, S.L. (2000), "The effect of laser power and traverse speed on microstructure, porosity, and build height in laser-deposited Ti-6Al-4V", Scripta Materialia, Vol. 43 No. 4, pp. 299-305.

Krishna, B.V., Bose, S. and Bandyopadhyay, A. (2007), "Laser processing of net-shape NiTi shape memory alloy", Metallurgical and Materials Transactions A, Vol. 38 No. 5, pp. 1096-1103.

Krishna, B.V., Bose, S. and Bandyopadhyay, A. (2007), "Low stiffness porous $\mathrm{Ti}$ structures for load-bearing implants", ACTA Biomaterialia, Vol. 3 No. 6, pp. 997-1006.

Kummailil, J., Sammarco, C., Skinner, D., Brown, C.A. and Rong, K. (2005), "Effect of select LENS ${ }^{\mathrm{TM}}$ processing parameters on the deposition of Ti-6Al-4V", fournal of Manufacturing Processes, Vol. 7 No. 1, pp. 42-50. 
Kuznetsov, A.V., Shaysultanov, D.G., Stepanov, N.D., Salishchev, G.A. and Senkov, O.N. (2012), "Tensile properties of an $\mathrm{AlCrCuNiFeCo}$ high-entropy alloy in ascast and wrought conditions", Materials Science and Engineering: A, Vol. 533, pp. 107-118.

LENS 1500 (2018), "LENS 1500 additive manufacturing controlled atmosphere system".

LENS Blisk Repair Solution (2014), "LENS blisk repair solution", available at: www.optomec.com/3d-printedmetals/lens-emerging-applications/blisk-repair/

Lewandowski, J.J. and Seifi, M. (2016), "Metal additive manufacturing: a review of mechanical properties", Annual Review of Materials Research, Vol. 46 No. 1, pp. 151-186.

Lewis, G.K. and Schlienger, E. (2000), "Practical considerations and capabilities for laser assisted direct metal deposition", Materials Eீ Design, Vol. 21 No. 4, pp. 417-423.

Lu, Z.L., Li, D.C., Lu, B.H., Zhang, A.F., Zhu, G.X. and Pi, G. (2010), "The prediction of the building precision in the laser engineered net shaping process using advanced networks", Optics and Lasers in Engineering, Vol. 48 No. 5, pp. 519-525.

Manvatkar, V., Gokhale, A., Jagan Reddy, G., Venkataramana, A. and De, A. (2011), "Estimation of melt pool dimensions, thermal cycle, and hardness distribution in the laserengineered net shaping process of austenitic stainless steel", Metallurgical and Materials Transactions A, Vol. 42 No. 13, pp. 4080-4087.

Marshall, G.J., Thompson, S.M. and Shamsaei, N. (2016), "Data indicating temperature response of $\mathrm{Ti}-6 \mathrm{Al}-4 \mathrm{~V}$ thinwalled structure during its additive manufacture via laser engineered net shaping", Data in Brief, Vol. 7, pp. 697-703.

Mazumder, J., Schifferer, A. and Choi, J. (1999), "Direct materials deposition: designed macro and microstructure", Materials Research Innovations, Vol. 3 No. 3, pp. 118-131.

Meneghetti, G., Rigon, D., Cozzi, D., Waldhauser, W. and Dabalà, M. (2017), "Influence of build orientation on static and axial fatigue properties of maraging steel specimens produced by additive manufacturing", Procedia Structural Integrity, Vol. 7, pp. 149-157.

Mohammed, M., Fitzpatrick, A., Malyala, S. and Gibson, I. (2016), "Customised design and development of patient specific 3D printed whole mandible implant", Proceedings of the 27th Annual International Solid Freeform Fabrication Symposium, pp. 1708-1717.

Mohammed, M.I., Tatineni, J., Cadd, B., Peart, G. and Gibson, I. (2017), "Advanced auricular prosthesis development by 3D modelling and multi-material printing", KNE Engineering, Vol. 2 No. 2, pp. 37-43.

Mohseni, H., Nandwana, P., Tsoi, A., Banerjee, R. and Scharf, T.W. (2015), "In situ nitrided titanium alloys: microstructural evolution during solidification and wear", ACTA Materialia, Vol. 83, pp. 61-74.

Mukherjee, T., Zhang, W. and DebRoy, T. (2017), "An improved prediction of residual stresses and distortion in additive manufacturing", Computational Materials Science, Vol. 126, pp. 360-372.

Murr, L.E., Gaytan, S.M., Ramirez, D.A., Martinez, E., Hernandez, J., Amato, K.N., Shindo, P.W., Medina, F.R. and Wicker, R.B. (2012), "Metal fabrication by additive manufacturing using laser and electron beam melting technologies", Fournal of Materials Science \& Technology, Vol. 28 No. 1, pp. 1-14.

Neela, V. and De, A. (2009), "Three-dimensional heat transfer analysis of LENSTM process using finite element method", The International fournal of Advanced Manufacturing Technology, Vol. 45 Nos 9/10, pp. 935-943.

Nickel, A.H., Barnett, D.M. and Prinz, F.B. (2001), “Thermal stresses and deposition patterns in layered manufacturing", Materials Science and Engineering: A, Vol. 317 Nos 1/2, pp. 59-64.

Osman, R.B., van der Veen, A.J., Huiberts, D., Wismeijer, D. and Alharbi, N. (2017), "3D-printing zirconia implants; a dream or a reality? An in-vitro study evaluating the dimensional accuracy, surface topography and mechanical properties of printed zirconia implant and discs", fournal of the Mechanical Behavior of Biomedical Materials, Vol. 75, pp. 521-528.

Kobryn, P.A. and Semiatin, S.L. (2001), "The laser additive manufacture of Ti-6Al-4V”, fOM, Vol. 53 No. 9, pp. 40-42.

Palcic, I., Balazic, M., Milfelner, M. and Buchmeister, B. (2009), "Potential of laser engineered net shaping (LENS) technology", Materials and Manufacturing Processes, Vol. 24 Nos 7/8, pp. 750-753.

Parthasarathy, J., Starly, B. and Raman, S. (2011), “A design for the additive manufacture of functionally graded porous structures with tailored mechanical properties for biomedical applications", Fournal of Manufacturing Processes, Vol. 13 No. 2, pp. 160-170.

Paul, C.P., Jain, A., Ganesh, P., Negi, J. and Nath, A.K. (2006), "Laser rapid manufacturing of colmonoy-6 components", Optics and Lasers in Engineering, Vol. 44 No. 10, pp. 1096-1109.

Pegues, J., Leung, K., Keshtgar, A., Airoldi, L., Apetre, N., Iyyer, N. and Shamsaei, N. (2017), "Effect of process parameter variation on microstructure and mechanical properties of additively manufactured TI-6al-4v", Solid Freeform Fabrication, pp. 62-74.

Pi, G., Zhang, A., Zhu, G., Li, D. and Lu, B. (2011), "Research on the forming process of three-dimensional metal parts fabricated by laser direct metal forming", The International fournal of Advanced Manufacturing Technology, Vol. 57 Nos 9/12, pp. 841-847.

Pinkerton, A.J. (2007), "An analytical model of beam attenuation and powder heating during coaxial laser direct metal deposition", Fournal of Physics D: Applied Physics, Vol. 40 No. 23, p. 7323.

Powell, J. (1983), "Laser cladding”.

Powell, J., Henry, P. and Steen, W. (1988), "Laser cladding with preplaced powder: analysis of thermal cycling and dilution effects", Surface Engineering, Vol. 4 No. 2, pp. 141-149.

Pratt, P., Felicelli, S.D. and Wang, L. (2008), "Residual stress measurement of laser-engineered net shaping AISI 410 thin plates using neutron diffraction", Metallurgical and Materials Transactions A, Vol. 39 No. 13, pp. 3155-3163.

Qi, H., Mazumder, J. and Ki, H. (2006), "Numerical simulation of heat transfer and fluid flow in coaxial laser cladding process for direct metal deposition", fournal of Applied Physics, Vol. 100 No. 2. 
Razavi, S.M.J., Bordonaro, G.G., Ferro, P., Torgersen, J. and Berto, F. (2018), "Fatigue behavior of porous Ti-6Al-4V made by laser-engineered net shaping", Materials, Vol. 11 No. 2, p. 284.

Joshi, S.C. and Sheikh, A.A. (2015), "3D printing in aerospace and its long-term sustainability", Virtual and Physical Prototyping, Vol. 10 No. 4, pp. 175-185.

Saboori, A., Gallo, D., Biamino, S., Fino, P. and Lombardi, M. (2017), "An overview of additive manufacturing of titanium components by directed energy deposition: microstructure and mechanical properties", Applied Sciences, Vol. 7 No. 9.

Salmi, A., Calignano, F., Galati, M. and Atzeni, E. (2018), "An integrated design methodology for components produced by laser powder bed fusion (L-PBF) process", Virtual and Physical Prototyping, Vol. 13 No. 3, pp. 191-202.

Sathiya, P., Panneerselvam, K. and Abdul Jaleel, M.Y. (2012), "Optimization of laser welding process parameters for super austenitic stainless steel using artificial neural networks and genetic algorithm", Materials $\mathcal{E}$ Design (1980-2015)), Vol. 36, pp. 490-498.

Shamsaei, N., Yadollahi, A., Thompson, S.M. and Bian, L. (2015), "An overview of direct laser deposition for additive manufacturing; part II: mechanical behavior, process parameter optimization and control", Additive Manufacturing, Vol. 8, pp. 12-35.

Sharman, A.R.C., Hughes, J.I. and Ridgway, K. (2018), "Characterisation of titanium aluminide components manufactured by laser metal deposition", Intermetallics, Vol. 93, pp. 89-92.

Shishkovsky, I. and Smurov, I. (2012), "Titanium base functional graded coating via 3D laser cladding", Materials Letters, Vol. 73, pp. 32-35.

Shun, T.-T. and Du, Y.-C. (2009), "Age hardening of the $\mathrm{Al} 0.3 \mathrm{CoCrFeNiC0.1}$ high entropy alloy", fournal of Alloys and Compounds, Vol. 478 Nos 1/2, pp. 269-272.

Smurov, I. (2008), "Laser cladding and laser assisted direct manufacturing", Surface and Coatings Technology, Vol. 202 No. 18, pp. 4496-4502.

Stepanov, N.D., Shaysultanov, D.G., Yurchenko, N.Y., Zherebtsov, S.V., Ladygin, A.N., Salishchev, G.A. and Tikhonovsky, M.A. (2015), "High temperature deformation behavior and dynamic recrystallization in CoCrFeNiMn high entropy alloy", Materials Science and Engineering: $A$, Vol. 636, pp. 188-195.

Sterling, A.J., Torries, B., Shamsaei, N., Thompson, S.M. and Seely, D.W. (2016), "Fatigue behavior and failure mechanisms of direct laser deposited Ti-6Al-4V", Materials Science and Engineering: $A$, Vol. 655, pp. 100-112.

Stoker, N.G., Mankovich, N.J. and Valentino, D. (1992), "Stereolithographic models for surgical planning: preliminary report", fournal of Oral and Maxillofacial Surgery, Vol. 50 No. 5, pp. 466-471.

Sun, G., Zhou, R., Lu, J. and Mazumder, J. (2015), "Evaluation of defect density, microstructure, residual stress, elastic modulus, hardness and strength of laser-deposited AISI 4340 steel”, ACTA Materialia, Vol. 84, pp. 172-189.

Syed, W.U.H., Pinkerton, A.J. and Li, L. (2005), "A comparative study of wire feeding and powder feeding in direct diode laser deposition for rapid prototyping", Applied Surface Science, Vol. 247 Nos 1/4, pp. 268-276.
Syed, W.U.H., Pinkerton, A.J. and Li, L. (2006), “Combining wire and coaxial powder feeding in laser direct metal deposition for rapid prototyping", Applied Surface Science, Vol. 252 No. 13, pp. 4803-4808.

Terminology (2015), "Standard terminology for additive manufacturing - general principles - terminology".

Thompson, S.M., Bian, L., Shamsaei, N. and Yadollahi, A. (2015), "An overview of direct laser deposition for additive manufacturing; part I: transport phenomena, modeling and diagnostics", Additive Manufacturing, Vol. 8, pp. 36-62.

Toyserkani, E., Khajepour, A. and Corbin, S.F. (2004), Laser Cladding, CRC press.

Vandenbroucke, B. and Kruth, J.-P. (2007), "Selective laser melting of biocompatible metals for rapid manufacturing of medical parts", Rapid Prototyping fournal, Vol. 13 No. 4, pp. 196-203.

Wang, L., Felicelli, S., Gooroochurn, Y., Wang, P.T. and Horstemeyer, M.F. (2008), "Optimization of the LENS ${ }^{\circledR}$ process for steady molten pool size", Materials Science and Engineering: A, Vol. 474 Nos 1/2, pp. 148-156.

Wang, X., Deng, D., Hu, Y., Ning, F., Wang, H., Cong, W. and Zhang, H. (2018), "Overhang structure and accuracy in laser engineered net shaping of Fe-Cr steel”, Optics $\mathcal{E}$ Laser Technology, Vol. 106, pp. 357-365.

Wen, S.Y., Shin, Y.C., Murthy, J.Y. and Sojka, P.E. (2009), "Modeling of coaxial powder flow for the laser direct deposition process", International fournal of Heat and Mass Transfer, Vol. 52 Nos 25/26, pp. 5867-5877.

Wong, K.V. and Hernandez, A. (2012), "A review of additive manufacturing”, ISRN Mechanical Engineering, Vol. 2012, pp. 1-10.

Xiong, Y., Smugeresky, J.E. and Schoenung, J.M. (2009), "The influence of working distance on laser deposited WCCo", Fournal of Materials Processing Technology, Vol. 209 No. 10, pp. 4935-4941.

Xiong, Y., Hofmeister, W.H., Smugeresky, J.E., Delplanque, J.-P. and Schoenung, J.M. (2012), "Investigation of atypical molten pool dynamics in tungsten carbide-cobalt during laser deposition using in-situ thermal imaging", Applied Physics Letters, Vol. 100 No. 3, p. 034101.

Xue, W., Krishna, B.V., Bandyopadhyay, A. and Bose, S. (2007), "Processing and biocompatibility evaluation of laser processed porous titanium", ACTA Biomaterialia, Vol. 3 No. 6, pp. 1007-1018.

Yadollahi, A., Shamsaei, N., Thompson, S.M. and Seely, D. W. (2015), "Effects of process time interval and heat treatment on the mechanical and microstructural properties of direct laser deposited 316L stainless steel", Materials Science and Engineering: A, Vol. 644 No. 1, pp. 171-183.

Yadroitsev, I., Gusarov, A., Yadroitsava, I. and Smurov, I. (2010), "Single track formation in selective laser melting of metal powders", fournal of Materials Processing Technology, Vol. 210 No. 12, pp. 1624-1631.

Yadroitsev, I., Thivillon, L., Bertrand, P. and Smurov, I. (2007), "Strategy of manufacturing components with designed internal structure by selective laser melting of metallic powder", Applied Surface Science, Vol. 254 No. 4, pp. 980-983.

Yan, L., Chen, X., Li, W., Newkirk, J. and Liou, F. (2016), "Direct laser deposition of Ti-6Al-4V from elemental 
powder blends", Rapid Prototyping fournal, Vol. 22 No. 5, pp. 810-816.

Yang, N. (2009), "Concentration model based on movement model of powder flow in coaxial laser cladding", Optics $\mathcal{E}$ Laser Technology, Vol. 41 No. 1, pp. 94-98.

Yevko, V., Park, C., Zak, G., Coyle, T. and Benhabib, B. (1998), "Cladding formation in laser-beam fusion of metal powder", Rapid Prototyping fournal, Vol. 4 No. 4, pp. 168-184.

Yu, J., Lin, X., Ma, L., Wang, J., Fu, X., Chen, J. and Huang, W. (2011), "Influence of laser deposition patterns on part distortion, interior quality and mechanical properties by Laser Solid Forming (LSF)", Materials Science and Engineering: A, Vol. 528 No. 3, pp. 1094-1104.

Zadi-Maad, A. and Basuki, A. (2018), "The development of additive manufacturing technique for nickel-base alloys: a review", AIP Conference Proceedings, Vol. 1945 No. 1, p. 020064 .

Zhai, Y., Galarraga, H. and Lados, D.A. (2016), "Microstructure, static properties, and fatigue crack growth mechanisms in Ti-6Al-4V fabricated by additive manufacturing: LENS and EBM", Engineering Failure Analysis, Vol. 69, pp. 3-14.

Zhai, Y., Galarraga, H. and Lados, D.A. (2016), "Microstructure, static properties, and fatigue crack growth mechanisms in Ti-6Al-4V fabricated by additive manufacturing: LENS and EBM", Engineering Failure Analysis, Vol. 69, pp. 3-14.

Zheng, B., Topping, T. and Smugeresky, J.E. (2010), "The influence of Ni-Coated TiC on laser-deposited IN625 metal matrix composites", Metallurgical and Materials Transactions $A$, Vol. 41 No. 3, pp. 568-573.

Zheng, B., Zhou, Y., Smugeresky, J.E., Schoenung, J.M. and Lavernia, E.J. (2008), "Thermal behavior and microstructural evolution during laser deposition with laserengineered net shaping: part I. numerical calculations", Metallurgical and Materials Transactions A, Vol. 39 No. 9, pp. 2228-2236.

\section{Corresponding author}

Mojtaba Izadi can be contacted at: Izmo@deakin.edu.au

For instructions on how to order reprints of this article, please visit our website: 